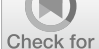

updates

Cite as

Nano-Micro Lett.

(2019) $11: 47$

Received: 15 March 2019

Accepted: 13 May 2019

Published online: 3 June 2019

(C) The Author(s) 2019

\section{In Situ X-ray Absorption Spectroscopy Studies of Nanoscale Electrocatalysts}

\author{
Maoyu Wang ${ }^{1}$, Líney Árnadóttir ${ }^{1}$, Zhichuan J. Xu ${ }^{2}$, Zhenxing Feng ${ }^{1} \bowtie$ \\ $\triangle$ Zhenxing Feng, zhenxing.feng@oregonstate.edu \\ 1 School of Chemical, Biological, and Environmental Engineering, Oregon State University, Corvallis, \\ OR 97331, USA \\ 2 School of Materials Science and Engineering, Nanyang Technological University, Singapore 639798, \\ Singapore
}

\title{
HIGHLIGHTS
}

- This is the first review paper on the studies of electrocatalysts using advanced in situ X-ray absorption spectroscopy (XAS).

- This paper reviews the literatures to-date on new applications of in situ XAS (e.g., single-atom catalysts, surface reactions, nanoparticle size, and site occupation) that traditional XAS has not touched.

- This review focuses mostly on recent publications after 2010 .

\begin{abstract}
Nanoscale electrocatalysts have exhibited promising activity and stability, improving the kinetics of numerous electrochemical reactions in renewable energy systems such as electrolyzers, fuel cells, and metal-air batteries. Due to the size effect, nano particles with extreme small size have high surface areas, complicated morphology, and various surface terminations, which make them different from their bulk phases and often undergo restructuring during the reactions. These restructured materials are hard to probe by conventional ex-situ characterizations, thus leaving the true reaction centers and/or active sites difficult to determine. Nowadays, in situ techniques, particularly X-ray absorption spectroscopy (XAS), have become an important tool to

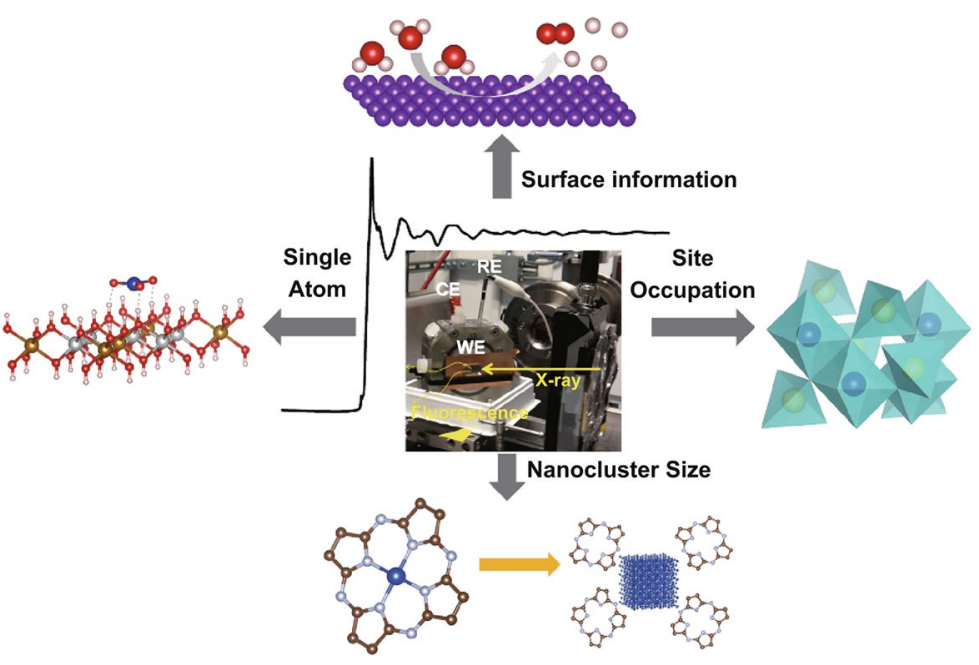
obtain oxidation states, electronic structure, and local bonding environments, which are critical to investigate the electrocatalysts under real reaction conditions. In this review, we go over the basic principles of XAS and highlight recent applications of in situ XAS in studies of nanoscale electrocatalysts.
\end{abstract}

KEYWORDS X-ray absorption spectroscopy; Electrocatalyst; Nanoscale; In situ experiments 


\section{Introduction}

In the past decade, the growing global demands for energy and increasing awareness of environment pollution have motivated researchers to develop renewable energy devices that can convert green energy (e.g., solar and wind) into electricity or store them in clean fuels such as hydrogen [1-3]. Among various energy conversion technologies, fuel cells are the most efficient and clean systems as they can generate electricity by consuming hydrogen (hydrogen oxidation reaction, HOR) and oxygen (oxygen reduction reaction, ORR) that can be electrochemically reduced from water (hydrogen evolution and oxygen evolution reactions, or HER and OER, respectively) [4-6]. In addition, electrochemical carbon dioxide reduction reaction (CO2RR) is merging as one of the most promising methods to reduce the environmental pollution, as it can not only lower the greenhouse gas level, but also produce useful hydrocarbon (e.g., $\mathrm{CH}_{4}$ ) for fuel cells and other energy processes [7-10]. However, all these electrochemical reactions experience severe sluggish reaction kinetics, so electrocatalysts are necessary to improve the efficiency. In recent years, nanoscale catalysts have shown great advantages to catalyze electrochemical reactions due to their high surface area, tunable morphology, and a large amount of active sites [11-14]. For example, Zhou et al. demonstrated that a hollow nanospheres with mesoporous $\mathrm{N}$-doped carbon shells and well-dispersed $\mathrm{Fe}_{3} \mathrm{O}_{4}$ nanoparticles can exhibit much higher ORR catalytic activity and better electrochemical durability than commercial Pt/C [15]. Additionally, Gupta et al. reported a bifunctional $\mathrm{FeCoNi}$ alloy nanoparticles on nitrogen-doped graphene that can reach the same ORR on-set potential as commercial Pt/C and $65 \mathrm{mV}$ more negative OER on-set potential than commercial Ir metal [16]. On the hydrogen reaction side, Li et al. developed a selective solvothermal synthesis of nano- $\mathrm{MoS}_{2}$, which shows superior electrocatalytic activity in HER compared to other $\mathrm{MoS}_{2}$ catalysts [17]. Efforts have also been made on the CO2RR, as Cyrille et al. found a molecular Fe catalysts could electrochemically reduce $\mathrm{CO}_{2}$ to $\mathrm{CO}$ with a $\mathrm{CO}$ faradaic yield above $90 \%$ at low overpotential $(0.465 \mathrm{~V})$ through 50 million turnovers [18].

Although nanoscale catalysts exhibit intriguing activity and selectivity, their reaction sites are not well characterized. Furthermore, these nanocatalysts may experience restructuring during the reactions; thus, the true active phases for promoting electrochemical reactions are different from the initial material. For example, it has been found that a Pt-cluster-based catalyst is oxidized to a mixture of $\operatorname{Pt}(0)$, $\mathrm{Pt}(\mathrm{II})$, and $\mathrm{Pt}(\mathrm{IV})$, which are more active than $\mathrm{Pt}(0)$ during ORR [19]. Furthermore, several cases have shown that copper or copper compounds undergo reversible reconstruction processes to form different types of nano-clusters that promote CO2RR with high efficiency and superior selectivity (to either $\mathrm{CO}$ or $\mathrm{CH}_{4}$ ) [20, 21]. Therefore, it is critical to understand the structure of these materials, and particularly how they evolve during electrochemical reactions to identify the real structure-property relationships. Advanced characterizations are necessary to obtain such information, and in situ measurements are important to capture the structures that only exist in intermediate reaction states to understand the reaction processes. In situ X-ray absorption spectroscopy (XAS) has become a powerful technique to obtain oxidization states, electronic structure, and local coordination environment under reaction conditions. It can characterize many different materials including liquid and solid in either crystalline or amorphous structure, from bulk, to nanoscale and even a single atom [22-24]. In this review, we will go through the basic principles of XAS emphasizing the recent development of in situ XAS with applications in nanoscale electrocatalysis as well as further advancement of XAS in emerging research fields.

\section{Fundamentals of XAS}

When X-ray passes through a material, the intensity is attenuated (Fig. 1a). According to Beer's law, this attenuation can be characterized by the absorption coefficient according to Eq. 1,

$I_{\mathrm{t}}=I_{0} \mathrm{e}^{-\mu(E) t}$

where $I_{0}$ is the incident X-ray intensity, $I_{\mathrm{t}}$ is the transmitted X-ray intensity, $t$ is the sample thickness, and $(E)$ is the absorption coefficient that is dependent on the photon energy [22, 23, 25]. XAS measures the energy-dependent fine structure of the X-ray absorption coefficient [23-27]. When the incident X-ray energy is lower than the binding energy of the electron in the element's orbital (say, $s$ orbital), the electrons are not excited to highest unoccupied state or the vacuum. The lack of strong X-ray and electron interaction leads to the flat region shown in Fig. 1b; however, some 

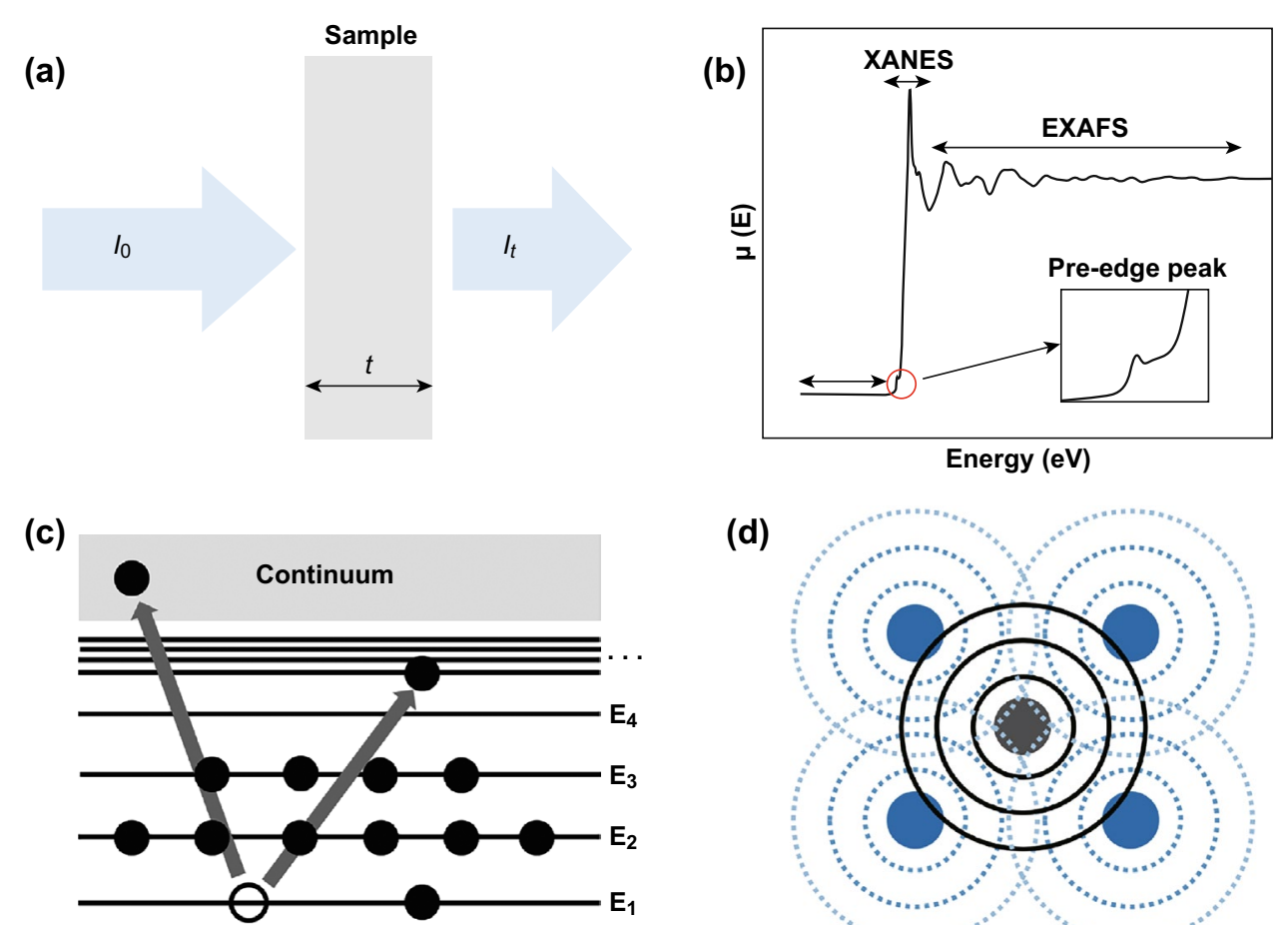

(d)

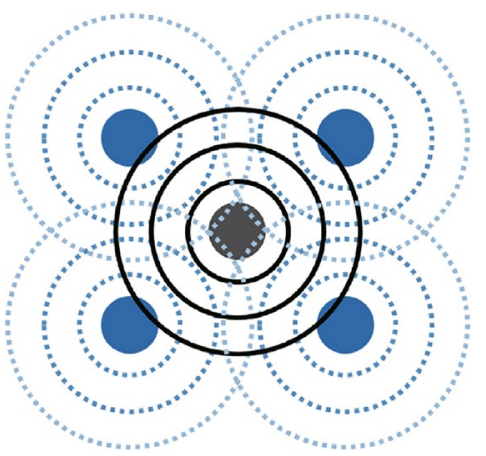

Fig. 1 a Schematic of incident and transmitted X-ray beam. b Schematic of XAS including the pre-edge, XANES, and EXAFS regions. c Schematic of the X-ray absorption process and electron excited process, the black circle is electrons. $\mathbf{d}$ Schematic of interference pattern creating by the outgoing (solid black lines) and reflected (dashed blue lines) photoelectron waves between absorbing atom (gray) and its nearest atoms (purple). (Color figure online)

unfavored transitions such as $1 s$ to $3 d$ in transition metals will appear as a pre-edge peak (Fig. 1b) [22-25]. Once the $\mathrm{X}$-ray energies are high enough to excite core electrons to the unoccupied state (Fig. 1c), X-ray is strongly absorbed leading to a large jump in the spectrum, which is called the $\mathrm{X}$-ray absorption near edge structure (XANES) (Fig. 1b). This region is sensitive to the oxidization state and electronic structure of the detected elements as the core electron energy is affected by the electron distribution in the valence state [22-25]. With the further increase in X-ray energies, the core electrons excited to continuum state (Fig. 1c) form the outgoing and scattering wave interference with neighboring atoms (Fig. 1d). The constructive or deconstructive interferences of the outgoing and scattering waves form the wiggles in the extended X-ray absorption fine structure (EXAFS) region (Fig. 1b), which reflects local atomic structure such as bond distance and coordination number [28-30].

There are three basic modes for XAS signal collections, namely transmission, fluorescence, and electron yield modes (Fig. 2). Transmission mode measures the difference between incident and directly transmitted X-ray intensity (Fig. 1a). In transmission mode, concentrated and homogenous samples are recommended to increase the difference for high-quality data, in accordance with the Beer's law [22-24]. In contrast, fluorescence mode measures the emitted X-rays from the elements (Fig. 2a). The intensity of this fluorescence is proportional to the absorption caused by the investigated element, but could also be affected by self-absorption effect. Thus, it is good for dilute, and works for, non-homogenous samples [22-24]. Instead of measuring the emitted fluorescence, we can also measure the emitted photoelectrons from the sample itself. Because of the relative short mean free path of photoelectrons, this mode is surface sensitive [22-24], while the two other modes are bulk sensitive. As XAS mainly probes the local structure, it can be used to measure many different materials including liquid and solid.

XAS requires synchrotron sources that can tune the $\mathrm{X}$-ray energy easily. The fast development of synchrotron X-ray source (about 92 synchrotron sources around the world) has enabled the wide applications of XAS. Recently, XAS can also be performed on the benchtop instrument, making it more accessible in the laboratory 
(a)

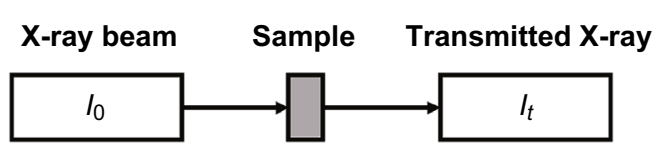

Transmission Mode
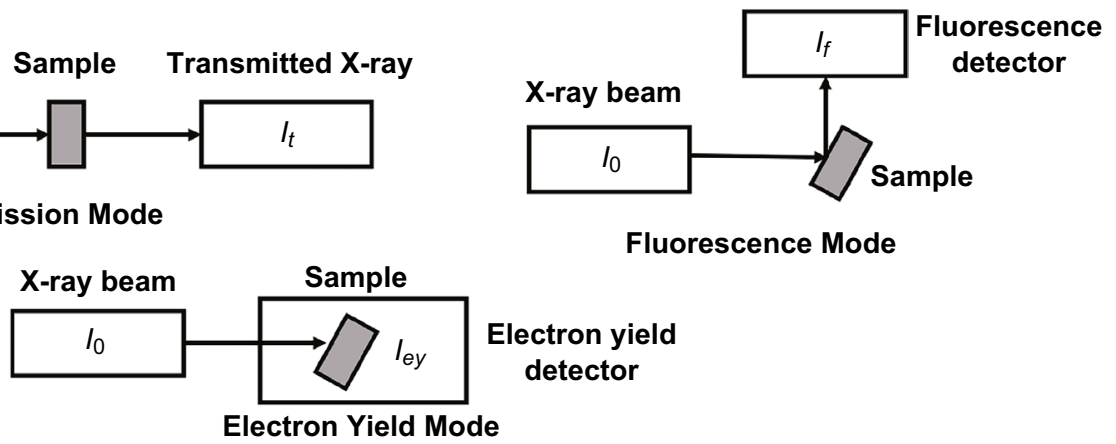

Fluorescence Mode

Electron Yield Mode

(b)

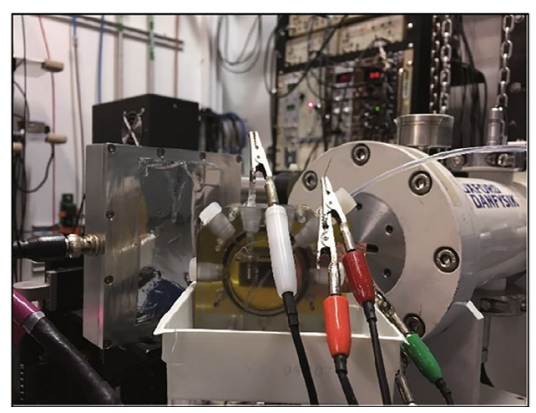

(c)

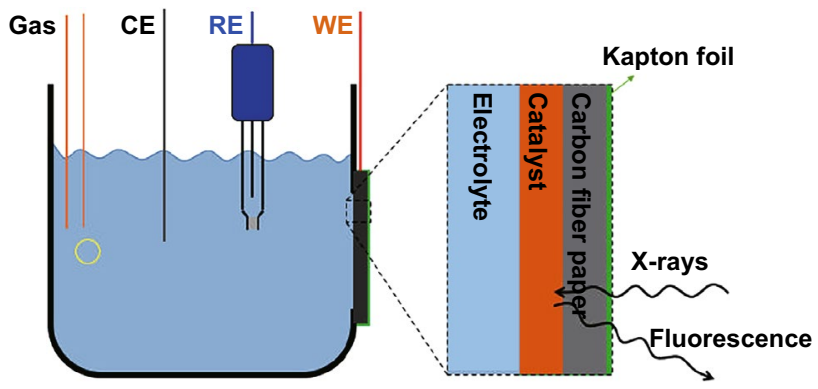

Fig. 2 a Schematic of the experiment setup for three different XAS detection modes: transmission, fluorescence, and electron yield mode. b Photo of a real electrochemical cell for in situ XAS experiment setup. $\mathbf{c}$ Schematic structure of the electrochemical cell for in situ XAS setup experiments. Reprinted with permission from Ref. [21]

[31, 32]. The use of hard X-ray (energy higher than $5 \mathrm{keV}$ ) can be beneficial for in situ measurements [21, 33, 34]. It is relatively hard to do in situ electrochemical reaction in many of the most advanced characterization tools such as scanning transmission electron microscopy, transmission electron microscopy, and X-ray photoelectron spectroscopy, which are frequently applied in the vacuum condition. In comparison, the continuous tunable hard X-ray running at the ambient condition, used in XAS, is much easier to operate in in situ experiment. The advanced electrochemical cell design also simplifies the operation of in situ XAS experiments. Figures 2b, c show a customdesigned XAS cell for electrochemical reactions in Feng's group. It has four necks used for the gas inlet, and outlet, a reference electrode, and a counter electrode. The gas inlet and outlet make it possible to study reactions involving gases such as ORR and CO2RR. The front window is covered by the electrocatalyst as working electrode loaded on the carbon fiber paper, which is fixed by Kapton foil/ tape to prevent any leakage of electrolyte. Combined with the reference and counter electrode, it is built as a threeelectrode (or multi-electrode) reaction cell. Furthermore, the cell can hold up to $30 \mathrm{~mL}$ liquid that guarantees enough electrolyte for the electrochemical reactions. Different from laboratory-based electrochemical tests that involve a rotating disk to reduce the diffusion effect in the electrolyte, this XAS cell has been shown to serve as an excellent platform for in situ mechanistic studies [9, 21]. Currently, XAS is used not only to probe oxidization states and local structure but also to investigate nano-cluster size, element site occupation in the crystal lattice, and atomic disperse molecular structure due to the well-developed XAS techniques and analysis software.

\section{In Situ XAS Probing Oxidization State and Local Structure}

Most electrocatalytic reactions involve chemical absorption and electron transfers, leading to the change of oxidization state and local structure, which is the short-range bonding structure, within $5 \AA$, respectively $[9,21,33-35]$. These changes can be reversible and are difficult to detect by ex situ characterizations. XAS, particularly in situ, is capable of probing the oxidization states and local structure of 
selected elements under real reaction conditions. By using this technique, Sasaki et al. found a reversible oxidization state change of Pt monolayer electrocatalyst supported on $\mathrm{Pd} / \mathrm{C}$, which showed better ORR stability than commercial Pt/C [35]. The Pt monolayer was oxidized to Pt oxide with ascending potential $(0.41-1.51 \mathrm{~V})$, and Pt oxide was reduced back to $\mathrm{Pt}$ with descending potential (1.51-0.41 V), which is reflected by the change of the Pt L-edge XAS white line intensity (Fig. 3a, b). In addition, three distinct peaks at $11,573,11,603$, and $11,624 \mathrm{eV}$ are observed in all the XANES spectra in Fig. 3a, b that indicates the coexistence of two different $\mathrm{Pt}$ species ( $\mathrm{Pt} \& \mathrm{PtO}_{2}$ ). The percentage of the two Pt species is quantified by a linear combination analysis of XANES and suggests that the percentage of $\mathrm{PtO}_{2}$ formation per surface $\mathrm{Pt}$ atom on the $\mathrm{Pt} / \mathrm{C}$ is almost 3.5 times higher than $\mathrm{Pt}$ monolayers. The formed $\mathrm{PtO}_{2}$ dissolves in the electrolyte, leading to decreased stability of the $\mathrm{Pt} / \mathrm{C}$. The formed and dissolved $\mathrm{PtO}_{2}$ reaction intermediate products are not detected by ex situ characterizations, and the difficulty in identifying this dissolvable intermediate, results in increased complexity in studying the catalyst stability. In contrast to this single-element nanocatalysts case, many materials have multiple elements such as alloy, metals supported on oxides, mixed metal oxides, and mixed metal hydroxyl, which are also widely used as electrocatalysts [36-38] but tracking each element's change to determine (a)

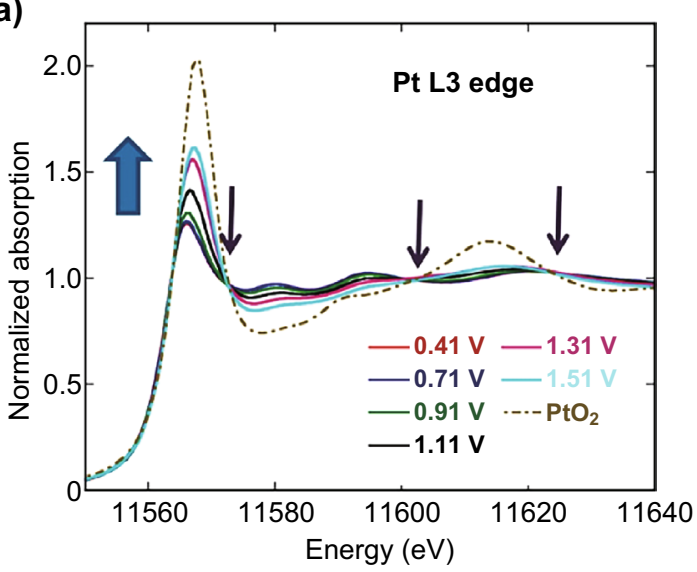

(c)

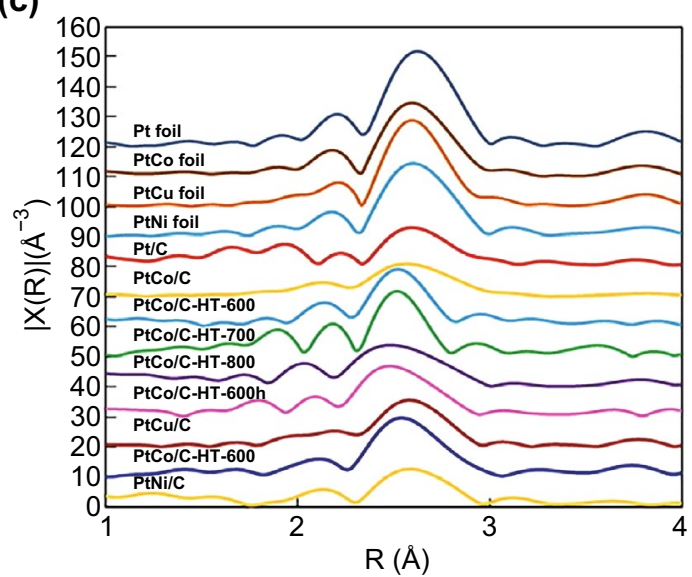

(b)

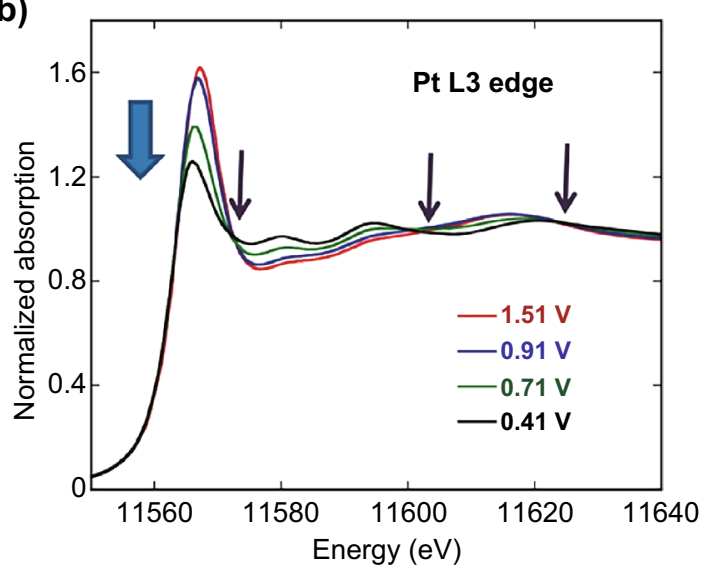

(d)

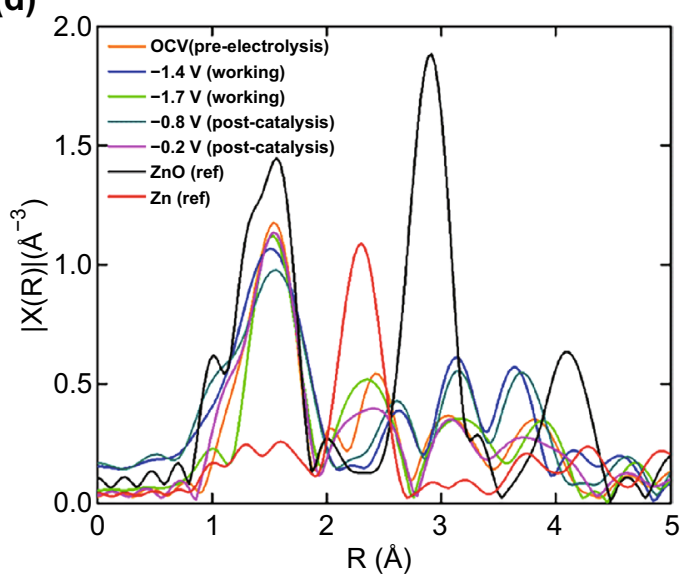

Fig. 3 In situ XANES for $\mathrm{Pt}_{\mathrm{L}}$ edge of carbon-supported Pt nanoparticles at potentials a ascending from 0.41 to $1.51 \mathrm{~V}$ and $\mathbf{b}$ descending from 1.51 to $0.41 \mathrm{~V}$ in $1 \mathrm{M} \mathrm{HClO}_{4}$. Also shown (yellowish green dashed line) is ex situ XANES from commercial PtO $\mathrm{X}_{2}$. Three distinct isosbestic points are observed at 11.573, 11.603, and $11.624 \mathrm{keV}$ as designated by arrows. Reprinted with permission from Ref. [35]. c Fourier transform of $\mathrm{k}^{3}$-weighted Pt- $\mathrm{L}_{\mathrm{III}}$ edge EXAFS oscillation of Pt foil, $\mathrm{PtCo}, \mathrm{PtCu}, \mathrm{PtNi}$ alloy foils, $\mathrm{Pt} / \mathrm{C}, \mathrm{PtCo} / \mathrm{C}, \mathrm{PtCo} / \mathrm{C}-\mathrm{HTs}, \mathrm{PtCu} / \mathrm{C}, \mathrm{PtCu} / \mathrm{C}-\mathrm{HT}$, and $\mathrm{PtNi} / \mathrm{C}$ at $0.4 \mathrm{~V}$ versus RHE. Reprinted with permission from Ref. [38]. d Fourier transforms of Zn K-edge EXAFS spectra of the PorZn catalyst electrode at different potentials (V vs. SHE). ZnO and $\mathrm{Zn}$ are used as references. Reprinted with permission from Ref. [9] 
whether catalysts have synergistically effect is very challenging. XAS, which is an element-specific technique, offers great advantages to study each element of the system separately; combined with in situ measurements, it provides the possibility to determine the role of multiple elements for catalytic reactions. For example, Wang et al. reported that the Fe-doped $\mathrm{Ni}(\mathrm{OH})_{x}$, with a high OER catalytic activity, forms $\mathrm{Ni}^{3.6+}$ and $\mathrm{Fe}^{4+}$ during electrochemical processes [33]. The $\mathrm{Fe}^{4+}$ leads to a strong covalent $\mathrm{Fe}-\mathrm{O}$ bond, which interacts with $\mathrm{Ni}$ to form $\mathrm{Ni}-\mathrm{O}-\mathrm{Fe}$ bond, and the charge transfer between $\mathrm{Ni}$ and Fe through a "Ni-O-Fe" bond is the key reaction step, which results in high catalytic performance. These findings heavily rely on the analysis of in situ XANES measurements, which provide critical evidence for the synergistic effect of multiple metal elements as highly active nano-electrocatalysts.

Besides the oxidization states probed by XANES, the local coordination information provided by EXAFS can also be used to determine the active site of electrocatalysts or the role of multiple metal elements. Kaito et al. reported a core-shell Pt/Au electrocatalyst exhibiting higher ORR activity [39]. Their ex situ EXAFS studies found a shorter $\mathrm{Pt}-\mathrm{Pt}$ bond in the $\mathrm{Pt} / \mathrm{Au}$ than that in the $\mathrm{Pt} / \mathrm{C}$ or $\mathrm{Pt}$ foil, but the shorter Pt-Pt was believed to contribute to the high ORR activity. Two years later, the same group, by using in situ XAS, identified the Pt-Pt bond distance as the primarily descriptor for ORR activity regardless of the atomic ordering or morphology of the different Pt nano-alloy [38]. A clearly linear trend was discovered increasing the ORR area specific activity with the decrease in the $\mathrm{Pt}-\mathrm{Pt}$ bond (Fig. 3c). For instance, $\mathrm{Pt}_{2} \mathrm{Co}$ (PtCo/C-HT-600), which has the shortest Pt-Pt bond distance of the metals studied, exhibits the highest ORR activity which is approximately ten times more active per unit surface area than the commercial Pt/C at the reaction condition of $0.4 \mathrm{~V}$ versus $\mathrm{RHE}$ (Fig. 3c). Different from the synergistic effect of Fe-doped $\mathrm{Ni}(\mathrm{OH})_{x}$, here, the $\mathrm{Co}, \mathrm{Cu}$, and $\mathrm{Ni}$ in the Pt alloy are used to restrain the Pt-Pt bond, and the Pt itself is the active site for the catalytic reaction. It is common that catalysts metal centers play a major role for catalyzing reactions; however, there are some catalytic materials with metal as a non-active center $[9,40]$. A $\mathrm{Zn}$-porphyrin has been reported as a high activity electrocatalyst to convert $\mathrm{CO}_{2}$ to $\mathrm{CO}$ with $\mathrm{Zn}$ as a redox-innocent metal center [9]. In situ XAS shows no obvious change in $\mathrm{Zn}$ oxidization state, but variations in $\mathrm{Zn}$ EXAFS are found, which may be caused by the reduction in the porphyrin ligand or binding of molecules on the $\mathrm{Zn}$ site (Fig. 3d). Here, the porphyrin ligand, instead of the metal, works as a redox center for the $\mathrm{CO}_{2} \mathrm{RR}$.

Many mechanistic studies of heterogeneous catalysts are complimented by density functional theory (DFT) calculation of reaction mechanisms, active sites, and adsorbate interactions. Many of these studies have used an indirect comparison between the XAS analysis and DFT calculations (e.g., activation energies at various reaction coordinates) to confirm active sites and favorable reaction paths, such as role of different active sites in HER activity of different CoP-based catalysts [41, 42], modified $\mathrm{IrO}_{2}$ and nanoscale $\mathrm{SrRuO}_{3}$ catalyst for OER [43, 44], zeolite chemistry under reactive SCR conditions [45, 46], and many more [47-50]. Coupling of DFT calculations with XAS simulations [51] and implementation of different spectroscopy modeling modules into common computational tools for materials modeling have made direct theoretical predictions and analysis of XAS spectra more accessible and provided molecular insights into catalytic reaction mechanism and active sites. Some of the most commonly used computer codes to calculate XAS spectra are FEFF, an ab initio code, developed by John Rehr, which is widely used in the field for multiple scattering calculations of X-ray spectra [26, 30, 52]. Other common computational tools are XSpectra, a post-processing tool, implemented into Quantum Expresso [53-55], an open-source electronic-structure calculations code, and CASTEP which recently added a core-level spectroscopy tool, but CASTEP is commonly used for materials modeling based on first-principles [56]. Using this combined approach, researchers have studied zeolites under reactive conditions and showed how $\mathrm{H}_{2} \mathrm{O}$ and $\mathrm{NH}_{3}$ adsorptions can be distinguished through the different $\mathrm{Cu}-\mathrm{O}$ and $\mathrm{Cu}-\mathrm{N}$ valence to core $\mathrm{X}$-ray emission lines [45]. Theoretical XANES spectra for adsorbates on metal surfaces, based on DFT calculations, have shown general good agreement between experiments and theory [57-59]. For example, Diller et al. used dispersion-corrected DFT with transition potential approach [60] to compare carbon K-edge XANES spectra for porphine on $\mathrm{Ag}(111)$ and $\mathrm{Cu}(111)$ and found a very good agreement between experiments and theory with moderate computational effort (Fig. 4) [61]. XAS studies of reactions on surfaces have similarly benefitted from the combination of XAS- and DFT-predicted XAS spectra. A recent illustration of this is given by Saveleva et al. who identified the formation of an electrophilic oxygen species 


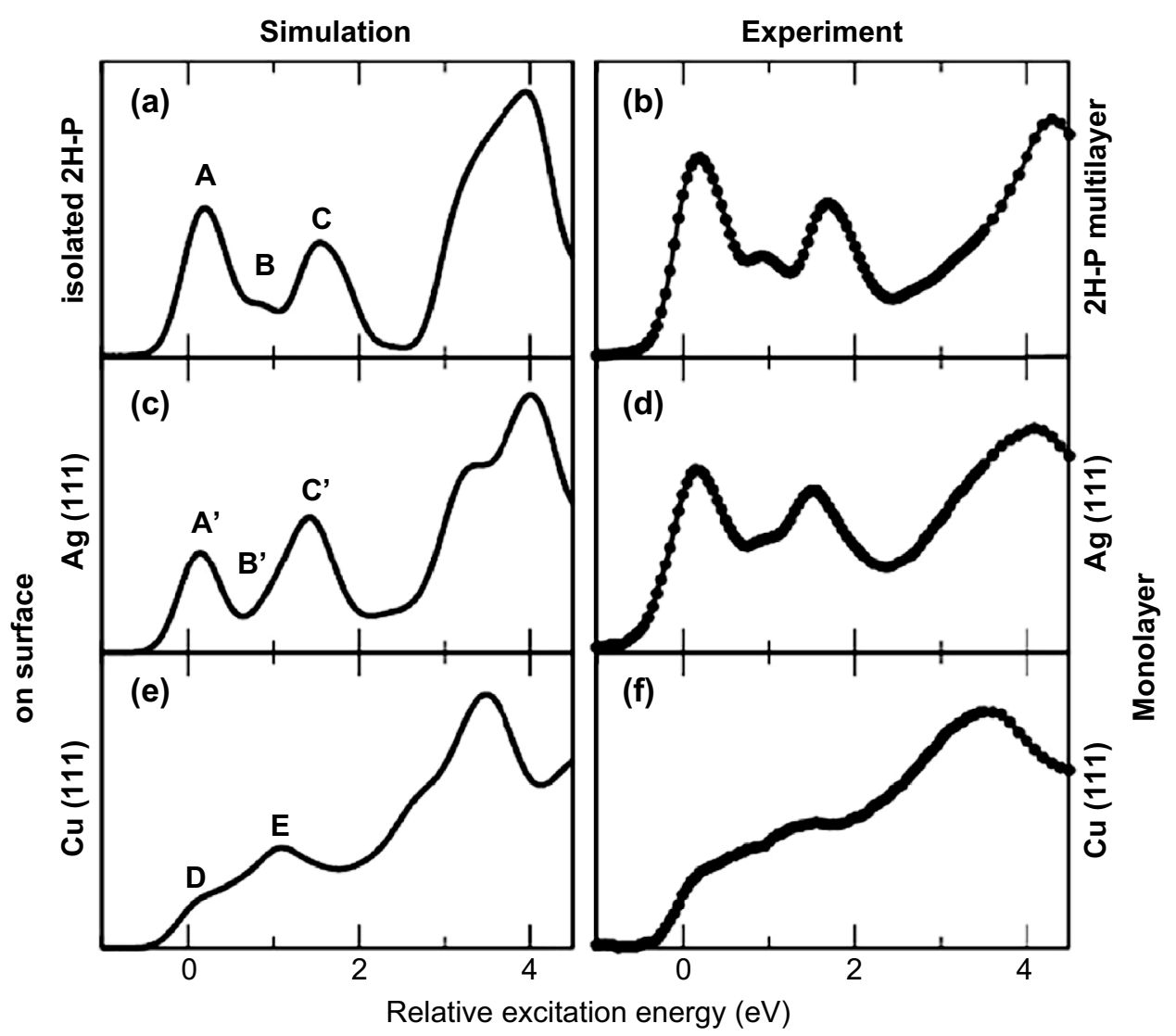

Fig. 4 Comparison of experimental and simulated C K-edge NEXAFS spectra for 2-H porphine adsorbed on $\mathrm{Ag}(111)$ and $\mathrm{Cu}(111)$. Reprinted with permission from Ref. [61]

during OER on iridium oxides based on DFT calculations of the O K-edge XAS peaks [62].

\section{Probing Site Occupation}

Compared to precious metals, nanoscale metal oxides such as perovskite and spinel are becoming more and more popular as electrocatalysts as they contain earth-abundant and cost-effective elements [2, 6, 12, 36]. These oxides can have complicated crystal structures and various polymorphs, and the elements may occupy multiple crystal sites $[3,37$, 63-65]. The crystal structure is a bulk property that can be studied by X-ray diffraction (XRD), but the site occupation requires local or short-range information that is hard to be probed by XRD. The distribution of elements at different sites, however, could influence the catalytic performance and thus is a critical parameter to obtain [3, 37, 63, 65]. A notable example is spinel oxide. Atoms in spinel octahedral
(Oh) site have relatively short bonding distance compared to atoms in the tetrahedral (Td) site, as shown in Fig. 5a. This difference can be distinguished by EXAFS, as shown in Fig. 5b, and the site occupation can then be further quantified by model-based structure refinement. Wang et al. synthesized metal oxide $\mathrm{Co}_{3} \mathrm{O}_{4}$ in spinel structure, which shows reasonable OER activity [63]. The Co occupies both $\mathrm{Td}$ site and $\mathrm{Oh}$ site, but only the $\mathrm{Co}^{2+}$ in tetrahedral site plays an active role in the catalytic reaction. This conclusion was reached by using EXAFS that determines the site occupation of Co (Fig. 5b). Co in the Oh site has shorter Co-Co scattering path $(\sim 2.4 \AA)$ than Co in Td site $(3 \AA)$, and those scattering paths in Fourier-transformed EXAFS are not phase-corrected. In situ XAS shows the local structure change of $\mathrm{Co}_{3} \mathrm{O}_{4}$ and suggests the formation of $\mathrm{CoOOH}$ intermediate species during the reaction. By comparing with the controlled samples of $\mathrm{ZnCo}_{2} \mathrm{O}_{4}$ and $\mathrm{AlCo}_{2} \mathrm{O}_{4}$, in which the $\mathrm{Co}^{3+}$ in $\mathrm{Oh}$ site is replaced by $\mathrm{Zn}$ and $\mathrm{Al}$, respectively, 

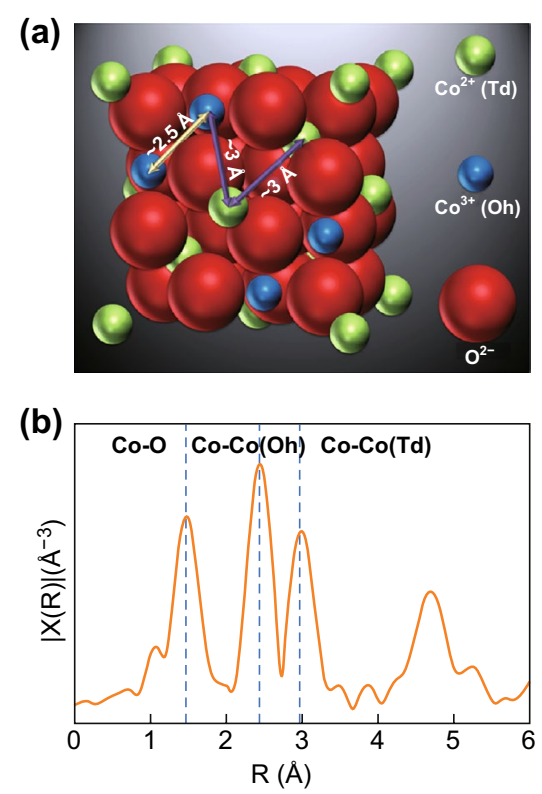
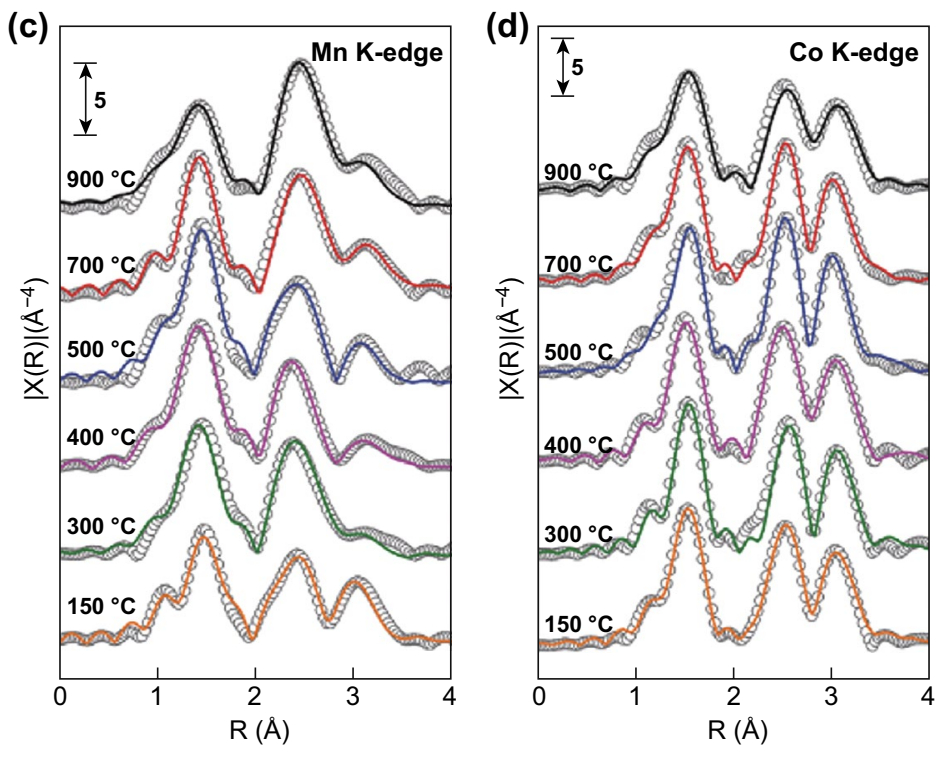

Fig. 5 a The relation of interatomic distance between atom $(\mathrm{Oh})$ and atom (Td) in spinel structure. b Co K-edge EXAFS spectra for $\mathrm{Co}_{3} \mathrm{O}_{4}$, the interatomic distances are shorter than the actual values owing to the fact that Fourier transform (FT) spectra were not phase-corrected. Reprinted with permission from Ref. [63]. EXAFS $\mathrm{k}^{3} \chi(\mathrm{R})$ spectra (gray circles) and fitting results (solid lines) of $\mathrm{MnCo}_{2} \mathrm{O}_{4}$ at $\mathbf{c} \mathrm{Mn}$ and $\mathbf{d} \mathrm{Co} \mathrm{K}$-edge. Reprinted with permission from Ref. [3]

the $\mathrm{CoOOH}$ is formed on the $\mathrm{Td}$ site, and is determined to be an active site for OER instead of $\mathrm{Co}^{2+}$ itself.

However, this study does not provide the Co distribution in $\mathrm{Td}$ and $\mathrm{Oh}$ sites, and the formation of $\mathrm{CoOOH}$ as intermediate product is based on the previous study. In a more recent study, Wei et al. performed a systematic investigation of different nanoscale transition metal spinel materials and utilized EXAFS together with model-based analysis to calculate site occupation of $\mathrm{Mn}$ atoms in $\mathrm{Td}$ and $\mathrm{Oh}$ sites [3]. By tuning the synthesis temperatures, the amount of $\mathrm{Mn}$ in the $\mathrm{Oh}$ site can be modified. The model-based analysis of ex situ XAS not only demonstrates the characteristic Oh peak (around $2.5 \AA$ ) and Td peak (around $3 \AA$ ) as shown in Fig. 5 c, d, but also estimates the amount of Mn occupation in the two sites. By using the linear combination method to analyze XANES, the Mn valence state can be accurately determined. Subsequently the electron occupancy can be quantified using the known spin state. By correlating this with the electrochemical performance, the number of, e.g., occupancy for $\mathrm{Mn}$ in the $\mathrm{Oh}$ site is suggested as activity descriptor for both ORR and OER. This conclusion relies on the co-refinements of Co and Mn EXAFS, which ensures the accuracy for the estimation of atom occupation at Td and Oh sites.

\section{Probing Nanoparticle Size and Shape}

The model-based EXAFS analysis can be further used to estimate the mean size and shape of nano-metal particles [66-68], providing important information to understand electrocatalysts' restructuring in electrochemical reactions. The outer shells of nanoparticles are under-coordinated, thus reducing the total average coordination number measured by EXAFS. The nearest neighbors' coordination number in nanoparticles has a nonlinear relation with the particle size diameter if the diameter is smaller than 3-5 $\mathrm{nm}[21,68]$. Figure $6 \mathrm{~b}$ shows the coordination numbers of the first three shells of nearest neighbors for a cuboctahedral Cu nanocrystal as a function of the crystal size. This relationship is also highly dependent on the particle shape as the particle shape will influence the coordination number calculations. Many, extremely small, catalyst clusters are catalytic active [67], but EXAFS has become a premier method to investigate such small nano-cluster in electrochemical reactions. In many cases, the in situ XAS data could be nosier than ex situ ones due to the shorter data collection time, which makes the model-based fitting of EXAFS not accurate enough to determine the coordination number. In addition, the fitted coordination number has a common uncertainty around 1 , 
(a)

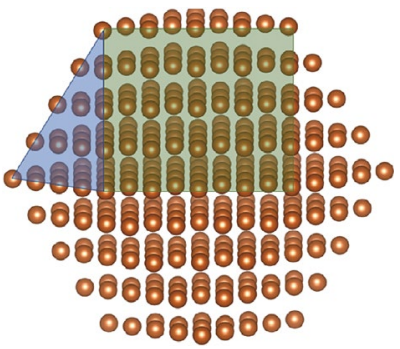

(b)

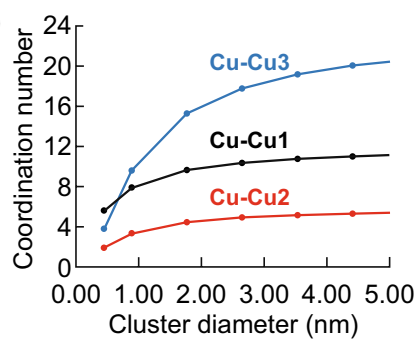

(c)

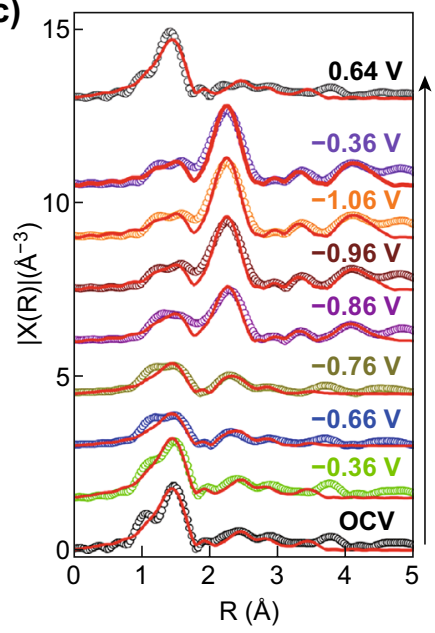

(d)

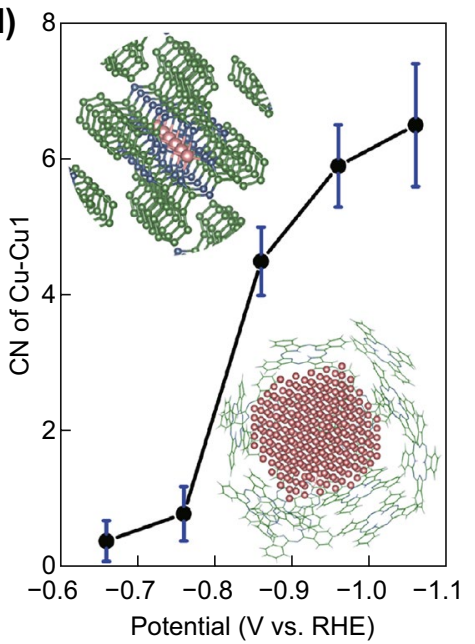

Fig. $6 \mathrm{Cu}$ nanocrystal model and its size-dependent $\mathrm{Cu}-\mathrm{Cu} \mathrm{CNs}$ for the first three shells of nearest neighbors. a A five-shell cuboctahedral $\mathrm{Cu}$ nanocrystal model. b Size-dependent $\mathrm{Cu}-\mathrm{Cu} \mathrm{CNs}$ for the first three shells of nearest neighbors for a cuboctahedral Cu nanocrystal. c Fitting results of the EXAFS spectra of the CuPc catalyst at different potentials in $\mathrm{CO}_{2}$-saturated $0.5 \mathrm{M}$ aqueous $\mathrm{KHCO}_{3}$. Fitted R-space. d First-shell $\mathrm{Cu}-\mathrm{Cu} \mathrm{CNs}$ of the $\mathrm{CuPc}$ catalyst at different potentials. The upper left inset shows the CuPc crystal structure, and the lower right inset illustrates a possible configuration of the $\mathrm{Cu}$ nano-clusters generated under the electrocatalytic conditions. Color key: green-C; blue- $\mathrm{N}$; pink-Cu. Error bars represent the uncertainty of $\mathrm{CN}$ determination from the EXAFS analysis. Reprinted with permission from Ref. [21]. (Color figure online)

thus adding additional error in particle size determination. Therefore, it is recommended to combine the model-based fitting with other characterization tools or theoretical calculation to predict the shape and size of nano-cluster. Due to the complexity of quantitative EXAFS analysis and particle size estimation, this application has not been widely used in electrocatalysis. A recent study reported a coexistence of square plan $\mathrm{Fe}^{2+}-\mathrm{N}_{4}$ and $\mathrm{Fe} / \mathrm{Fe}_{x} \mathrm{O}_{y}$ nanoparticles as an ORR descriptor for metal-nitrogen-coordinated non-precious-metal electrocatalyst systems [68]. Their model-based in situ EXAFS analysis reveals the change of $\mathrm{Fe}-\mathrm{Fe}$ and $\mathrm{Fe}-\mathrm{N}$ coordination during the reaction, and the appearance of under-coordinated $\mathrm{Fe}-\mathrm{Fe}$ bonding which is indicative of the formation of $\mathrm{Fe}$ nano-clusters. By referring to the electrochemical performance, $\mathrm{Fe}-\mathrm{N}$ is the active site for both $2 \mathrm{e}^{-}$transfer reaction to form $\mathrm{HO}_{2}{ }^{-}$and $2 \mathrm{e}^{-}$transfer reaction from $\mathrm{HO}_{2}{ }^{-}$to $\mathrm{HO}^{-}$in alkaline media. In contrast, in acidic media, the $\mathrm{Fe}-\mathrm{N}$ is the primary active site for $\mathrm{HO}_{2}{ }^{-}$formation, and Fe nanoparticles are the secondary active site for $\mathrm{HO}^{-}$. Although the authors did not report the nanoparticle size, the use of in situ EXAFS as well as model-based analysis plays an important role in determining the catalytically active sites and their corresponding role in the reaction.
Besides providing information related to the nanoparticle size, XAS is also useful to determine the shape of local coordination or nano-cluster formation during the reaction [33, 47, 69-71]. By analyzing the detailed coordination number of the nearest neighbors, one can construct the shape of the local building block. This is helpful when analyzing complex oxides that usually have both corner-sharing and edgesharing unit cell. Bediako et al. reported that a nickel-borate with high OER activity restructured to an edge-sharing $\mathrm{NiO}_{6}$ octahedra during anodization process [69]. They found that $\mathrm{Ni}-\mathrm{B}_{\mathrm{i}}$ films exhibit a greater than two orders of magnitude increase in OER activity after catalyst anodization, which is caused by the formation of active $\mathrm{Ni}(\mathrm{III} / \mathrm{IV})$ as probed by XANES. The model-based EXAFS analysis revealed an edge-sharing $\mathrm{NiO}_{6}$ octahedra with the domain size no smaller than $2 \mathrm{~nm}$ as the active sites. The analysis also suggested the short-range phase transition from $\beta$ - NiOOH like $\mathrm{Ni}-\mathrm{B}_{\mathrm{i}}$ films to $\gamma-\mathrm{NiOOH}$, and the $\gamma-\mathrm{NiOOH}$ may be intrinsically more OER active than $\beta-\mathrm{NiOOH}$. Similarly, Kanan et al. reported a cobalt phosphate with Co-oxo/hydroxo clusters with high OER activity [71]; the quantitative EXAFS analysis suggests that the edge-sharing $\mathrm{CoO}_{6}$ octahedra of Co-oxo/hydroxo is the OER active site. 
Frenkel et al., has summarized and reviewed the methods to model the structure and compositions of nanoparticles by EXAFS, which make the estimation of cluster size and shape easier [67]. Using Frenkel's strategy, Weng et al. reported that a copper(II) phthalocyanine exhibits a high methane selectivity and yield for CO2RR, which is due to copper nano-cluster formation during the catalytic reaction [21]. In their work, the in situ XAS suggests a reversible oxidization state change of $\mathrm{Cu}$ center by XANES: $\mathrm{Cu}(\mathrm{II})$ is reduced to $\mathrm{Cu}(0)$ at the lowest applied potential and oxidized back from $\mathrm{Cu}(0)$ to $\mathrm{Cu}(\mathrm{II})$ when the potential is returned to the starting value, namely open circle voltage. Concurrently, the EXAFS also finds a reversible local structure change. The qualitative analysis of EXAFS demonstrates a descending trend of $\mathrm{Cu}-\mathrm{N}$ coordination (corresponding to $1.5 \AA$ $\mathrm{Cu}-\mathrm{N}$ bond) and an ascending trend of $\mathrm{Cu}-\mathrm{Cu}$ coordination (referring to $2.2 \AA \mathrm{Au}-\mathrm{Cu}$ bond) when the applied potential decreases to the reaction potential with the highest methane selectivity and yield (Fig. 6c, d), while an opposite trend is observed when the potential goes back to open circle potential. With the coordination number of $\mathrm{Cu}-\mathrm{N}$ and $\mathrm{Cu}-\mathrm{Cu}$ at each applied potential and by using a cuboctahedral metallic copper model (Fig. 6a), the authors conclude that the formation of 2-nm metallic copper nanoparticles under the reaction conditions is the true active site. This conclusion is supported further by density functional theory (DFT) which confirms that $2 \mathrm{~nm}$ is smaller than the nucleation size requirement $(14.2 \mathrm{~nm})$ and ensures the reversible structure change.

\section{Probing Atomically Dispersed Catalyst Structure}

The ultimate development of nanoscale catalysts is toward single-atom catalysts. Atomically dispersed catalysts have high surface to bulk ratio and have been demonstrated to be promising candidates for numerous electrochemical reactions $[21,72,73]$. However, those materials have extremely low mass loadings, and majority of them are amorphous. It is challenging for most techniques to characterize those atomically dispersed catalyst to determine their structure information and related restructuring in reactions. The fluorescence mode of XAS is well suited to study samples in diluted or low concentration. The resolution of EXAFS is sub-angstrom, making XAS a unique probe to study single-atom catalysts. Wang et al. reported a nitrogen-coordinated single cobalt atom catalyst with respectable ORR activity and stability in acidic media [73]. The first coordination shell (around $1.4 \AA$ ) was fitted with Co-N, which shows a square planer $\mathrm{CoN}_{4}$ local structure (Fig. 7a).

The $\mathrm{CoN}_{4}$, with long-range disordered structure, was only found on samples annealed at $1100{ }^{\circ} \mathrm{C}$, but samples annealed at 600 and $800{ }^{\circ} \mathrm{C}$ showed a mixture of $\mathrm{Co}-\mathrm{N}$ and Co-Co coordination, suggesting only the sample annealed at $1100{ }^{\circ} \mathrm{C}$ is possibly atomically dispersed catalyst. The existence of $\mathrm{Co}-\mathrm{Co}$ coordination worsens the ORR performance, and the highly dispersed atomic $\mathrm{CoN}_{4}$ sites are the key to promote the high performance. In this study, XAS helped determine the local coordination environment around Co. However, it is hard to distinguish bonding with elements that are close in atomic numbers in XAS, such as $\mathrm{N}$ and $\mathrm{O}$ or $\mathrm{Co}$ and $\mathrm{Ni}$, due to the similarity in scattering path lengths and scattering intensities. In another study, Zhang et al. demonstrated a nitrogen-coordination single iron atom catalyst with almost the same catalytic activity as Pt/C [74]. The general EXAFS comparison between $\mathrm{Fe}-\mathrm{N}$ and $\mathrm{Fe}-\mathrm{O}$ (Fig. 7b) suggests almost same bond distance and similar peak feature. They did EXAFS fitting on those materials by modeling both $\mathrm{Fe}-\mathrm{N}$ and $\mathrm{Fe}-\mathrm{O}$ scattering paths and proposed two possible sceneries, one with four coordinated $\mathrm{Fe}-\mathrm{N}$ and the other with five coordinated $\mathrm{Fe}-\mathrm{O}$. With a help from soft XAS at the Fe L-edge, which confirms the Fe local tetrahedral structure environment, the authors conclude that $\mathrm{FeN}_{4}$ is a more reasonable structure which enhances the ORR activity.

Instead of relying on model-based analysis on one dimensional (1D) data (e.g., Fourier-transferred amplitude vs. $k$ ), recent development in EXAFS analysis can include both $\mathrm{k}$ - and R-space to generate a 2D view of the EXAFS local structure. This is called wavelet transform which replaces the infinitely expanded periodic oscillations in normal EXAFS Fourier transform by located wave trains for the integral transformation [75]. The method recovers the primary EXAFS signal without any loss of information, but the magnitude of wavelet transform provides a radial distance resolution as well as the resolution in the k-space, which helps distinguish the different light elements such as nitrogen and oxygen coordination [76]. An example is shown by Fei et al. who reported that atomic Co on nitrogen-doped graphene is highly active in aqueous media with very low overpotentials $(30 \mathrm{mV})$ [77]. To confirm the local coordination of Co, 

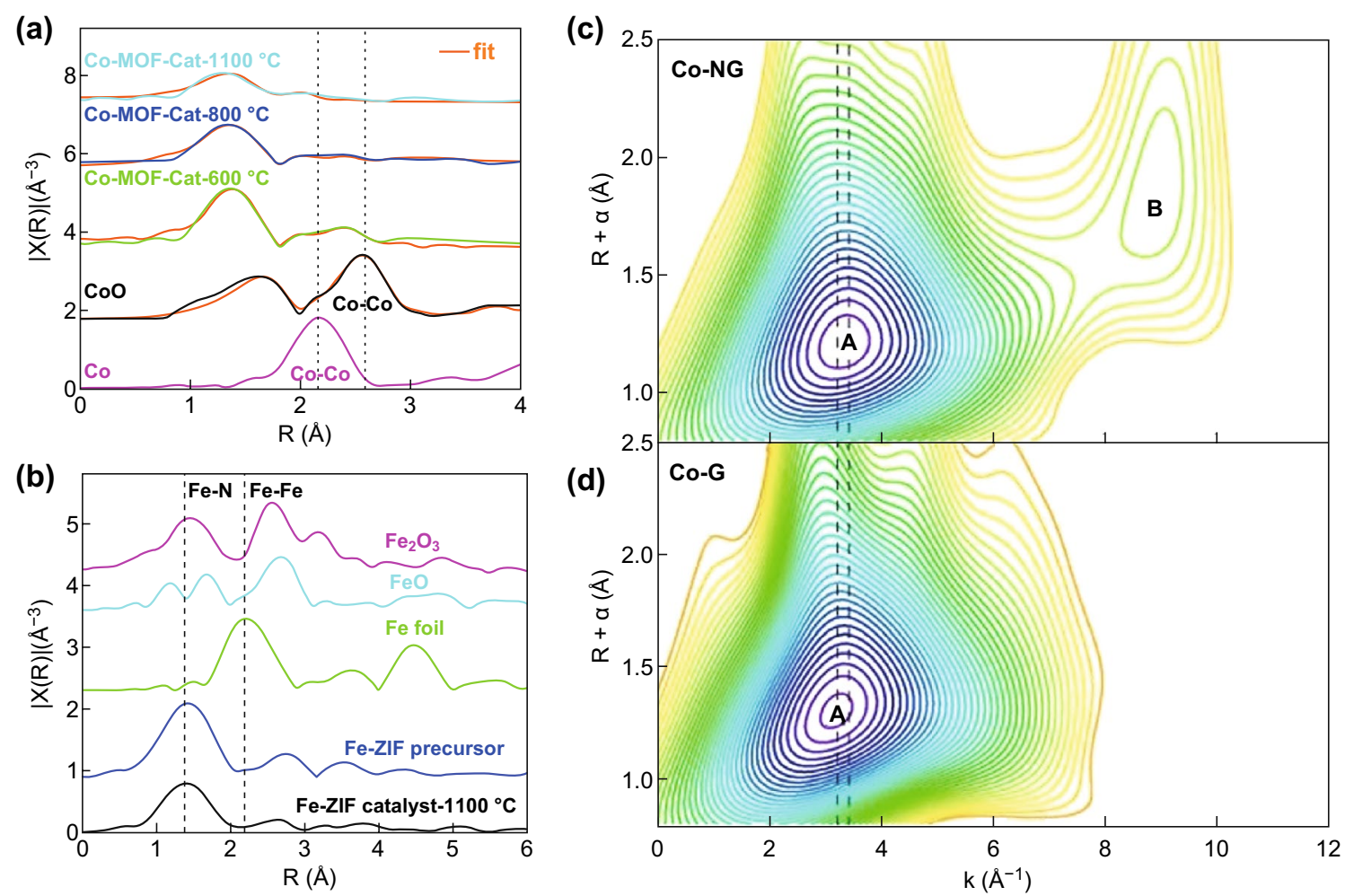

Fig. 7 a Co K-edge EXAFS data and fits (orange). Reprinted with permission from Ref. [73]. b Fe K-edge EXAFS spectra for chemically Fedoped ZIF before and after thermal activation. Reprinted with permission from Ref. [74]. Wavelet transforms for the $\mathbf{c}$ Co-NG and $\mathbf{d}$ Co-G. The location of the maximum A shifts from $3.2 \AA^{-1}$ for $\mathrm{Co}-\mathrm{G}$ to $3.4 \AA^{-1}$ for $\mathrm{Co}-\mathrm{NG}$, indicating the presence of Co-N bonding in Co-NG. The vertical dashed lines are provided to guide the eye. Reprinted with permission from Ref. [77]

the wavelet transform on EXAFS data of Co suggests the change of $\mathrm{Co}-\mathrm{C}$ bond in $\mathrm{Co}-\mathrm{G}$ to $\mathrm{Co}-\mathrm{N}$ bond in $\mathrm{Co}-\mathrm{NG}$ due to a little shift of peak A from 3.2 to $3.4 \AA^{-1}$ (Fig. 7c, d). They also found the heavy atom scattering such as $\mathrm{Co}-\mathrm{O}$ and $\mathrm{Co}-\mathrm{O}$ shows in the greater $K$-range, which will be helpful to identify the different coordinations. Although the wavelet transform help the analysis, it is still advised to combine it with other characterizations to provide further support when dealing with bonding with light elements.

Using ex situ XAS, many studies on atomically dispersed transition-metal catalysts have suggested that four nitrogencoordinated metal center is the active site for electrochemical reactions [72-74]. However, in situ XAS by Tylus et al. found the coexistence of $\mathrm{FeN}_{4}$ species and $\mathrm{Fe} / \mathrm{Fe}_{x} \mathrm{O}_{y}$ nanoparticles at reaction conditions [72]. In addition, recent study has reported that the nitrogen-doped carbon could also be the active site [78]. Strickland et al. studied a carbon-embedded metal atom clusters without direct metal-nitrogen coordination, which also achieve higher ORR activity than Pt/C in acidic media [40]. The qualitative EXAFS analysis finds only $\mathrm{Fe}-\mathrm{C}$ and $\mathrm{Fe}-\mathrm{Fe}$ coordination in FePhen@ MOF-ArNH 3 (FePhen) but no $\mathrm{Fe}-\mathrm{N}$ coordination. The in situ XAS studies demonstrated no change in both oxidization state and local structure, suggesting that FePhen is not directly involved in the ORR. Based on the XAS results, they believed that the $\mathrm{N}$-doped carbon mainly enhance the catalytic activity. Clearly, at the topic of single-atom catalysts, there will be more interesting, exciting, or sometimes surprising discoveries.Probing Surface Information

\section{Probing Surface Informaiton}

Most in situ XAS measurements rely on hard X-ray (energy higher than $5 \mathrm{keV}$ ) that is deeply penetrating, and thus not inherently surface sensitive [23, 24, 79]. However, electrocatalytic reactions occur on the surface of the materials while the XAS measures the bulk average, which limits the application of in situ XAS in the electrochemistry. Benefiting from the electron yield mode that collects electrons with 
short mean free path $(\sim 10 \AA)$, XAS can be tuned to gain surface sensitive [80]. Wang et al. applied such strategy to characterize the $\mathrm{Fe}$ and Co surface electronic orbits for $\mathrm{LaCo}_{x} \mathrm{Fe}_{1-x} \mathrm{O}_{3}$ perovskite electrocatalysts in ORR to predict the descriptor for the reaction pathway [81]. Thus far, there is no advanced in situ cell designed to work in electron yield mode as the electron excited by X-ray could be interfered by applied voltage in electrochemical reaction. Few reports can be found for surface-sensitive hard XAS. Despite the difficulties, hard XAS can still be used to probe the surface oxidization state and local structure change for some specific cases, particularly when reaction occurs only on the surface. For instance, the catalytic reaction for pseudo-capacitive mainly takes place on the surface or the near-surface region [37]. When using nanoparticles with size smaller than $10 \mathrm{~nm}$, the signal collected by XAS is actually dominated by surface contributions, making in situ XAS surface sensitive for the investigation of the pseudo-capacitance performance of spinel ferrite nanoparticles $\mathrm{XFe}_{2} \mathrm{O}_{4}(\mathrm{X}=\mathrm{Mn}, \mathrm{Fe}, \mathrm{Co}, \mathrm{Ni})$
[37]. For controlled parameters Fe, Wei et al. showed no oxidization state change during the charging process, and other elements such as $\mathrm{Co}$ and $\mathrm{Ni}$ also exhibit no detectable oxidation state change (Fig. 8a-d) [37]. However, the in situ XANES on Mn displays significant edge shift toward the higher energy as a function of the applied potential, and the corresponding EXAFS demonstrates that Mn occupying octahedral sites are responsive for the pseudo-capacitance. Due to the nano-size and surface reaction on spinel oxides, the information revealed by bulk-sensitive XAS becomes surface-sensitive due to the proportionally large contribution from the surface.

Furthermore, some other materials limit the reactions only to the surface [82-84]. Pelliccione et al. reported a PtRu catalyst for electrochemical oxidization of methanol on surface Ru atoms (Fig. 8e) [82]. The PtRu was synthesized by depositing $\mathrm{Ru}$ atoms only on the surface of Pt nanoparticles. Therefore, probing changes of Ru atoms turn a bulk-sensitive XAS into a surface technique. In this study, Ru gradually
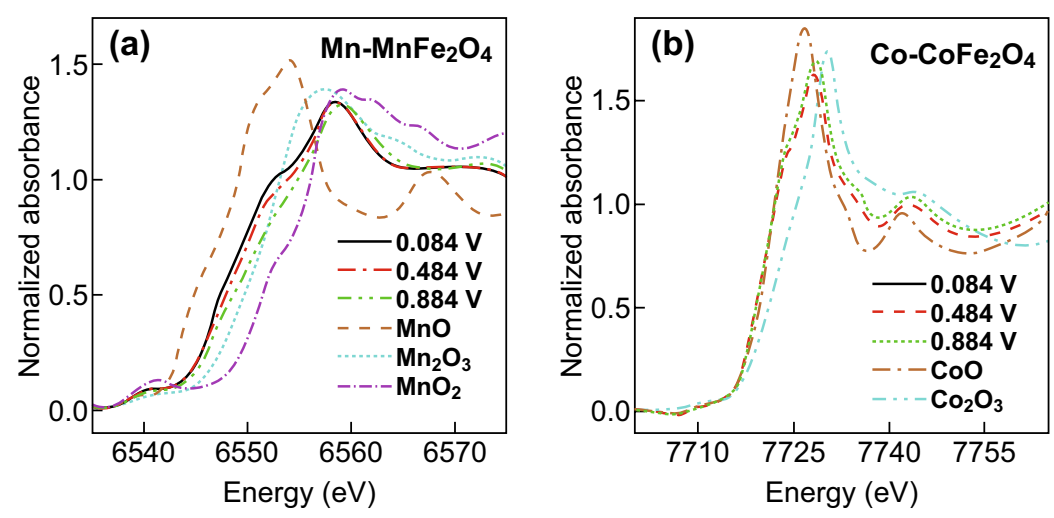

(e)
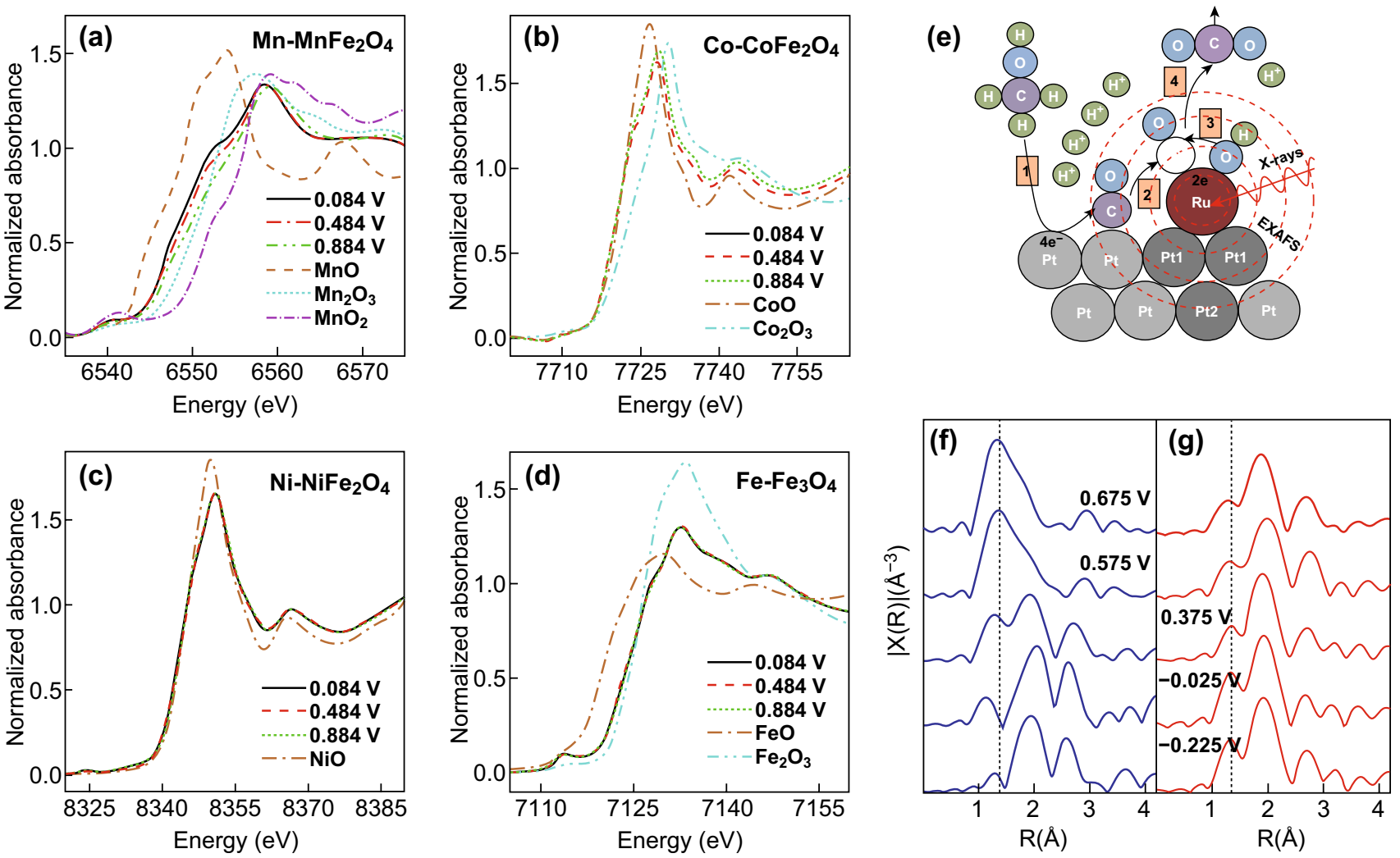

Fig. 8 K-edge XANES spectra of a Mn in $\mathrm{MnFe}_{2} \mathrm{O}_{4}$, b Co in $\mathrm{CoFe}_{2} \mathrm{O}_{4}$, c Ni in $\mathrm{NiFe}_{2} \mathrm{O}_{4}$, and d Fe in $\mathrm{Fe}_{3} \mathrm{O}_{4}$ under various applied potentials. Reprinted with permission from Ref. [37]. e Schematic of the surface reaction of the Ru atoms. R-space graphs as a function of applied potential f without (blue) and $\mathbf{g}$ with (red) $\mathrm{CH}_{3} \mathrm{OH}$. Dotted line placed at ca. $1.4 \AA$ signifying a reference point for the oxygen peaks. Reprinted with permission from Ref. [82]. (Color figure online) 
oxidizes from the metallic $\mathrm{Ru}$ to $\mathrm{Ru}(\mathrm{III}) / \mathrm{Ru}(\mathrm{IV})$ mixture at the highest potential in the background electrolyte, but in the presence of methanol, the Ru remains a mixture of $\mathrm{Ru}(0)$ and $\mathrm{Ru}(\mathrm{III})$. The model-based EXAFS analysis indicates the existence of $\mathrm{Ru}-\mathrm{O}$ to form $\mathrm{RuO}_{2}$-type coordination during the reaction in the background electrolyte in good agreement with the XAS experiments. Interestingly, in situ EXAFS finds the adsorption of $\mathrm{OH}$ and $\mathrm{CO}$ on the Ru atoms, and the oxidization of $\mathrm{CO}$ with coadsorbed $\mathrm{OH}$ occurs faster than oxidization of Ru to higher state (Fig. 8f-g), suggesting that $\mathrm{Ru}$ atoms promote the catalytic reaction. Another similar study used a well-defined monolayer of Pt on single crystal Rh(111) substrate for ORR. In this case, all Pt signals from XAS come from the Pt surface atoms and is therefore surface-sensitive [85]. The authors observed an ascending trend of Pt oxidization state with increased applied potential, and the EXAFS indicates an increasing coordination of Pt-O and a decreasing coordination of Pt-Pt, which is consistent with the change of oxidization state. The direct observation of $\mathrm{O}$ adsorbing on the $\mathrm{Pt} / \mathrm{Rh}(111)$ surface by in situ XAS also confirms the theoretical prediction. These examples demonstrate that the bulk-sensitive XAS can also work well in special cases to study the surface restructuring for nanoscale electrocatalysts.

\section{Other XAS Applications}

Although this review mainly focuses on hard XAS for in situ studies, the tender and soft XAS with energy lower than $5 \mathrm{keV}$ are also powerful tools to characterize detailed electronic structure such as the orbit spin and splitting for $3 d$ transition metal, and the transition-metal-oxygen covalency $[73,74,86]$. For example, Suntivich et al. reported a method to estimate the hybridization between transition metal and oxygen by using the oxygen K-edge XAS, and Hocking et al. demonstrated the $3 d$ orbit splitting in either octahedral or tetrahedral field with either high-spin or low-spin state by combining Fe L-edge XAS and theoretical simulation. In addition, soft XAS can probe bulk structure information such as crystalline or amorphous states and site occupation. For instance, Wu et al. distinguished amorphous and crystalline $\mathrm{SiO}_{2}$ through analysis of the peak features of the $\mathrm{Si}$ K-edge XAS by analyzing the peak features [87], and Zhang et al. demonstrated that the Fe L-edge XAS can be an indicator of tetrahedral and octahedral coordination [74].
Besides XAS working at different energies, there are two emerging types of XAS that provide temporal resolution, namely quick XAS and ultrafast XAS (or pump-and-probe spectroscopy). Due to lengthy time for data collection during XAS experiments, common in situ XAS measures the thermodynamic steady states. Quick XAS enables time-resolved XAS by using a dedicated X-ray monochromator to ensure rapid and repetitive energy scan, which results in measurements as short as couple of seconds [88]. Quick XAS can achieve 10-ms time resolution and can be applied to study dynamic or kinetic states in chemical and electrochemical reactions such as high rate delithiation behavior and nucleation process of nanoparticles $[89,90]$. Currently, the quick $\mathrm{X}$-ray absorption spectroscopy has also been used in the electrocatalysis field to resolve the reconstruction of the catalysts within several seconds [91, 92]. Pump-and-probe spectroscopy studies ultrafast electronic dynamics. In this technique, a stronger beam (pump) is used to excite the sample to generate a non-equilibrium state which exhibits the relaxation dynamics in the femtosecond or picosecond time regime, and a weaker beam (probe) is applied to observe the pump-induced changes in the optical constants [93, 94]. The function of changes in the optical constants with a time delay between pump-and-probe pluses describes the relaxation of electronic states in the sample. Therefore, ultrafast XAS can reach even higher time resolution (around femtosecond second) than quick XAS and can resolve intramolecular dynamics such as real-time observation of valence electron motion $[95,96]$.

\section{Conclusions}

In summary, we reviewed the recent progress of in situ XAS applied in the nanoscale electrocatalysis and discussed some other margining applications of XAS. XAS is a useful technique for understanding the local coordination environment, electronic structure, and oxidization state of selected elements. Moreover, in situ XAS can probe the material local structure and valence state under real reaction conditions to determine active site for rationalizing the design of electrocatalysts. XAS has almost no special requirements on sample type or preparation and is being applied to investigate the atomically dispersed materials in low loading and extremely small nano-clusters under harsh electrochemical reaction conditions. The advanced analysis software enables 
more quantitative analysis of the EXAFS to extract useful structural information such as surface absorption and nanocluster size and shape. In addition, the bulk-sensitive XAS can be used to probe the surface modification in some special cases such as for surface reaction or monolayer materials. With the development of new generation (e.g., 4th) synchrotron X-ray sources with higher flux, stronger coherence, and better time-resolution, XAS can be applied in merging fields to explore new frontiers in nanoscale electrocatalyst and related restructuring to facilitate the understanding of the structure-property relations for the design high-performance and low-cost electrocatalysts.

Acknowledgements Authors thank the useful discussion with Prof. Hailiang Wang from Yale University. This work was financially supported by start-up funds from Oregon State University. Part of authors' X-ray experiments was done at Advanced Photon Source, which is a U.S. Department of Energy (DOE) Office of Science User Facility operated for the DOE Office of Science by Argonne National Laboratory under Contract No. DE-AC0206CH11357. Part of authors' work using soft X-ray absorption spectroscopy was performed at beamline 6.3.1 of Advanced Light Source, which is an Office of Science User Facility operated for the U.S. DOE Office of Science by Lawrence Berkeley National Laboratory and supported by the DOE under Contract No. DEAC02-05CH11231.

Open Access This article is distributed under the terms of the Creative Commons Attribution 4.0 International License (http:// creativecommons.org/licenses/by/4.0/), which permits unrestricted use, distribution, and reproduction in any medium, provided you give appropriate credit to the original author(s) and the source, provide a link to the Creative Commons license, and indicate if changes were made.

\section{References}

1. Y. Nie, L. Li, Z.D. Wei, Recent advancements in Pt and Ptfree catalysts for oxygen reduction reaction. Chem. Soc. Rev. 44(8), 2168-2201 (2015). https://doi.org/10.1039/c4cs00484a

2. W. Xia, A. Mahmood, Z.B. Liang, R.Q. Zou, S.J. Guo, Earthabundant nanomaterials for oxygen reduction. Angew. Chem. Int. Ed. 55(8), 2650-2676 (2016). https://doi.org/10.1002/ anie. 201504830

3. C. Wei, Z.X. Feng, G.G. Scherer, J. Barber, Y. Shao-Horn, Z.C.J. Xu, Cations in octahedral sites: a descriptor for oxygen electrocatalysis on transition-metal spinels. Adv. Mater. 29(23), 1606800 (2017). https://doi.org/10.1002/adma.20160 6800

4. Z.L. Wang, D. Xu, J.J. Xu, X.B. Zhang, Oxygen electrocatalysts in metal-air batteries: from aqueous to nonaqueous electrolytes. Chem. Soc. Rev. 43(22), 7746-7786 (2014). https:// doi.org/10.1039/c3cs60248f
5. C.Z. Yuan, H.B. Wu, Y. Xie, X.W. Lou, Mixed transitionmetal oxides: design, synthesis, and energy-related applications. Angew. Chem. Int. Ed. 53(6), 1488-1504 (2014). https ://doi.org/10.1002/anie.201303971

6. Y. Wang, J. Li, Z.D. Wei, Transition-metal-oxide-based catalysts for the oxygen reduction reaction. J. Mater. Chem. A 6 , 8194-8209 (2018). https://doi.org/10.1039/c8ta01321g

7. N. Kornienko, Y.B. Zhao, C.S. Kiley, C.H. Zhu, D. Kim et al., Metal-organic frameworks for electrocatalytic reduction of carbon dioxide. J. Am. Chem. Soc. 137(44), 14129-14135 (2015). https://doi.org/10.1021/jacs.5b08212

8. Z. Weng, X. Zhang, Y.S. Wu, S.J. Huo, J.B. Jiang et al., Selfcleaning catalyst electrodes for stabilized $\mathrm{CO}_{2}$ reduction to hydrocarbons. Angew. Chem. Int. Ed. 56(42), 13135-13139 (2017). https://doi.org/10.1002/anie.201707478

9. Y.S. Wu, J.B. Jiang, Z. Weng, M.Y. Wang, D.L.J. Broere et al., Electroreduction of $\mathrm{CO}_{2}$ catalyzed by a heterogenized zn-porphyrin complex with a redox-innocent metal center. ACS Cent. Sci. 3(8), 847-852 (2017). https://doi.org/10.1021/acscentsci $.7 \mathrm{~b} 00160$

10. X. Zhang, Z.S. Wu, X. Zhang, L.W. Li, Y.Y. Li et al., Highly selective and active $\mathrm{CO}_{2}$ reduction electro-catalysts based on cobalt phthalocyanine/carbon nanotube hybrid structures. Nat. Commun. 8, 14675 (2017). https://doi.org/10.1038/ ncomms 14675

11. S. Sen, F. Sen, G. Gokagac, Preparation and characterization of nano-sized Pt-Ru/C catalysts and their superior catalytic activities for methanol and ethanol oxidation. Phys. Chem. Chem. Phys. 13(15), 6784-6792 (2011). https://doi. org/10.1039/c1cp20064j

12. Z.H. Wen, S.Q. Ci, F. Zhang, X.L. Feng, S.M. Cui et al., Nitrogen-enriched core-shell structured $\mathrm{Fe} / \mathrm{Fe}_{3} \mathrm{C}-\mathrm{C}$ nanorods as advanced electrocatalysts for oxygen reduction reaction. Adv. Mater. 24(11), 1399-1404 (2012). https://doi. org/10.1002/adma.201104392

13. M.B. Gawande, A. Goswami, T. Asefa, H.Z. Guo, A.V. Biradar et al., Core-shell nanoparticles: synthesis and applications in catalysis and electrocatalysis. Chem. Soc. Rev. 44(21), 7540-7590 (2015). https://doi.org/10.1039/c5cs0 $0343 \mathrm{a}$

14. F. Li, D.R. MacFarlane, J. Zhang, Recent advances in the nanoengineering of electrocatalysts for $\mathrm{CO}_{2}$ reduction. Nanoscale 10(14), 6235-6260 (2018). https://doi.org/10.1039/ C7NR09620H

15. D. Zhou, L.P. Yang, L.H. Yu, J.H. Kong, X.Y. Yao et al., $\mathrm{Fe} / \mathrm{N} / \mathrm{C}$ hollow nanospheres by Fe(iii)-dopamine complexation-assisted one-pot doping as nonprecious-metal electrocatalysts for oxygen reduction. Nanoscale 7(4), 1501-1509 (2015). https://doi.org/10.1039/c4nr06366j

16. S. Gupta, L. Qiao, S. Zhao, H. Xu, Y. Lin et al., Highly active and stable graphene tubes decorated with feconi alloy nanoparticles via a template-free graphitization for bifunctional oxygen reduction and evolution. Adv. Energy Mater. 6(22), 1601198 (2016). https://doi.org/10.1002/aenm.201601198

17. Y.G. Li, H.L. Wang, L.M. Xie, Y.Y. Liang, G.S. Hong, H.J. Dai, $\mathrm{MoS}_{2}$ nanoparticles grown on graphene: an advanced 
catalyst for the hydrogen evolution reaction. J. Am. Chem. Soc. 133(19), 7296-7299 (2011). https://doi.org/10.1021/ ja201269b

18. C. Costentin, S. Drouet, M. Robert, J.M. Saveant, A local proton source enhances $\mathrm{CO}_{2}$ electroreduction to Co by a molecular Fe catalyst. Science 338(6103), 90-94 (2012). https://doi. org/10.1126/science.1224581

19. Y.M. Li, J.H.C. Liu, C.A. Witham, W.Y. Huang, M.A. Marcus et al., A pt-cluster-based heterogeneous catalyst for homogeneous catalytic reactions: X-ray absorption spectroscopy and reaction kinetic studies of their activity and stability against leaching. J. Am. Chem. Soc. 133(34), 13527-13533 (2011). https://doi.org/10.1021/ja204191t

20. C.M. Gunathunge, X. Li, J.Y. Li, R.P. Hicks, V.J. Ovalle, M.M. Waegele, Spectroscopic observation of reversible surface reconstruction of copper electrodes under $\mathrm{CO}_{2}$ reduction. J. Phys. Chem. C 121(22), 12337-12344 (2017). https://doi. org/10.1021/acs.jpcc.7b03910

21. Z. Weng, Y.S. Wu, M.Y. Wang, J.B. Jiang, K. Yang et al., Active sites of copper-complex catalytic materials for electrochemical carbon dioxide reduction. Nat. Commun. 9, 415 (2018). https://doi.org/10.1038/s41467-018-02819-7

22. G. Bunker, Introduction to XAFS: A Practical Guide to X-ray Absorption Fine Structure Spectroscopy (Cambridge University Press, Cambridge, 2010)

23. S. Calvin, XAFS for Everyone (CRC Press, Boca Raton, 2018)

24. C.S. Schnohr, M.C. Ridgway, X-ray Absorption Spectroscopy of Semiconductors, Springer Series in Optical Sciences (Springer, Berlin, 2015)

25. D.C. Koningsberger, R. Prins, X-ray Absorption: Principles, Applications, Techniques of EXAFS, SEXAFS, and XANES (Wiley, New York, 1988)

26. J.J. Rehr, R.C. Albers, Theoretical approaches to X-ray absorption fine structure. Rev. Mod. Phys. 72(3), 621-654 (2000). https://doi.org/10.1103/RevModPhys.72.621

27. J.J. Rehr, A.L. Ankudinov, Progress in the theory and interpretation of XANES. Coord. Chem. Rev. 249(1-2), 131-140 (2005). https://doi.org/10.1016/j.ccr.2004.02.014

28. F. Boscherini, X-ray absorption fine structure in the study of semiconductor heterostructures and nanostructures. Charact. Semicond. Heterostruct. Nanostruct. (2008). https://doi. org/10.1016/B978-0-444-53099-8.00009-9

29. J. Als-Nielsen, D. McMorrow, Elements of Modern $X$-ray Physics (Wiley, New York, 2011). https://doi. org/10.1002/9781119998365

30. J.J. Rehr, J.J. Kas, F.D. Vila, M.P. Prange, K. Jorissen, Parameter-free calculations of X-ray spectra with FEFF9. Phys. Chem. Chem. Phys. 12(21), 5503-5513 (2010). https://doi. org/10.1039/b926434e

31. G.T. Seidler, D.R. Mortensen, A.J. Remesnik, J.I. Pacold, N.A. Ball, N. Barry, M. Styczinski, O.R. Hoidn, A laboratory-based hard $\mathrm{x}$-ray monochromator for high-resolution X-ray emission spectroscopy and X-ray absorption near edge structure measurements. Rev. Sci. Instrum. 85, 113906 (2014). https://doi. org/10.1063/1.4901599
32. A. Williams, Laboratory X-ray spectrometer for EXAFS and XANES measurements. Rev. Sci. Instrum. 54(2), 193-197 (1983). https://doi.org/10.1063/1.1137344

33. D.N. Wang, J.G. Zhou, Y.F. Hu, J.L. Yang, N. Han, Y.G. Li, T.K. Sham, In situ X-ray absorption near-edge structure study of advanced $\mathrm{NiFe}(\mathrm{OH})(\mathrm{x})$ electrocatalyst on carbon paper for water oxidation. J. Phys. Chem. C 119(34), 19573-19583 (2015). https://doi.org/10.1021/acs.jpcc.5b02685

34. K. Fottinger, J.A. van Bokhoven, M. Nachtegaal, G. Rupprechter, Dynamic structure of a working methanol steam reforming catalyst: in situ quick-EXAFS on $\mathrm{Pd} / \mathrm{ZnO}$ nanoparticles. J. Phys. Chem. Lett. 2(5), 428-433 (2011). https:// doi.org/10.1021/jz101751s

35. K. Sasaki, N. Marinkovic, H.S. Isaacs, R.R. Adzic, Synchrotron-based in situ characterization of carbon-supported platinum and platinum mono layer electrocatalysts. ACS Catal. 6(1), 69-76 (2016). https://doi.org/10.1021/acscatal.5b01862

36. Z. Cai, D.J. Zhou, M.Y. Wang, S.M. Bak, Y.S. Wu et al., Introducing $\mathrm{Fe}^{2+}$ into nickel-iron layered double hydroxide: local structure modulated water oxidation activity. Angew. Chem. Int. Ed. 57, 9392-9396 (2018). https://doi. org/10.1002/anie.201804881

37. C. Wei, Z.X. Feng, M. Baisariyev, L.H. Yu, L. Zeng et al., Valence change ability and geometrical occupation of substitution cations determine the pseudocapacitance of spinel ferrite $\mathrm{XFe}_{2} \mathrm{O}_{4}(\mathrm{X}=\mathrm{Mn} \mathrm{Co}, \mathrm{Ni}, \mathrm{Fe})$. Chem. Mater. 28(12), 4129-4133 (2016). https://doi.org/10.1021/acs.chemm ater.6b00713

38. T. Kaito, H. Tanaka, H. Mitsumoto, S. Sugawara, K. Shinohara et al., In situ X-ray absorption fine structure analysis of $\mathrm{PtCo}, \mathrm{PtCu}$, and PtNi alloy electrocatalysts: the correlation of enhanced oxygen reduction reaction activity and structure. J. Phys. Chem. C 120(21), 11519-11527 (2016). https://doi. org/10.1021/acs.jpcc.6b01736

39. T. Kaito, H. Mitsumoto, S. Sugawara, K. Shinohara, H. Uehara et al., K-edge X-ray absorption fine structure analysis of Pt/ $\mathrm{Au}$ core-shell electrocatalyst: evidence for short Pt-Pt distance. J. Phys. Chem. C 118(16), 8481-8490 (2014). https:// doi.org/10.1021/jp501607f

40. K. Strickland, M.W. Elise, Q.Y. Jia, U. Tylus, N. Ramaswamy et al., Highly active oxygen reduction non-platinum group metal electrocatalyst without direct metal-nitrogen coordination. Nat. Commun. 6, 7343 (2015). https://doi.org/10.1038/ ncomms 8343

41. F.L. Yang, Y.T. Chen, G.Z. Cheng, S.L. Chen, W. Luo, Ultrathin nitrogen-doped carbon coated with CoP for efficient hydrogen evolution. ACS Catal. 7(6), 3824-3831 (2017). https ://doi.org/10.1021/acscatal.7b00587

42. D.H. Ha, B.H. Han, M. Risch, L. Giordano, K.P.C. Yao, P. Karayaylali, Y. Shao-Horn, Activity and stability of cobalt phosphides for hydrogen evolution upon water splitting. Nano Energy 29, 37-45 (2016). https://doi.org/10.1016/j.nanoe n.2016.04.034

43. B.J. Kim, D.F. Abbott, X. Cheng, E. Fabbri, M. Nachtegaal et al., Unraveling thermodynamics, stability, and oxygen evolution activity of strontium ruthenium perovskite oxide. ACS 
Catal. 7(5), 3245-3256 (2017). https://doi.org/10.1021/acsca tal.6b03171

44. W. Sun, Y. Song, X.Q. Gong, L.M. Cao, J. Yang, Hollandite structure $\mathrm{K}_{x \approx 0.25} \mathrm{IrO}_{2}$ catalyst with highly efficient oxygen evolution reaction. ACS Appl. Mater. Interfaces 8(1), 820-826 (2016). https://doi.org/10.1021/acsami.5b10159

45. R.Q. Zhang, H. Li, J.S. McEwen, Chemical sensitivity of valence-to-core $\mathrm{X}$-ray emission spectroscopy due to the ligand and the oxidation state: a computational study on $\mathrm{Cu}-\mathrm{SSZ}-13$ with multiple $\mathrm{H}_{2} \mathrm{O}$ and $\mathrm{NH}_{3}$ adsorption. J. Phys. Chem. C 121(46), 25759-25767 (2017). https://doi.org/10.1021/acs. jpcc.7b04309

46. R.Q. Zhang, J.S. McEwen, Local environment sensitivity of the $\mathrm{Cu}$ k-edge XANES features in $\mathrm{Cu}-\mathrm{SSZ}-13$ : analysis from first-principles. J. Phys. Chem. Lett. 9(11), 3035-3042 (2018). https://doi.org/10.1021/acs.jpclett.8b00675

47. D. Friebel, M.W. Louie, M. Bajdich, K.E. Sanwald, Y. Cai et al., Identification of highly active $\mathrm{Fe}$ sites in $(\mathrm{Ni}, \mathrm{Fe}) \mathrm{OOH}$ for electrocatalytic water splitting. J. Am. Chem. Soc. 137(3), 1305-1313 (2015). https://doi.org/10.1021/ja511559d

48. M.A. Soldatov, A. Martini, A.L. Bugaev, I. Pankin, P.V. Medvedev et al., The insights from X-ray absorption spectroscopy into the local atomic structure and chemical bonding of metal-organic frameworks. Polyhedron 155, 232-253 (2018). https://doi.org/10.1016/j.poly.2018.08.004

49. J.J. Willis, A. Gallo, D. Sokaras, H. Aljama, S.H. Nowak et al., Systematic structure property relationship studies in palladium catalyzed methane complete combustion. ACS Catal. 7(11), 7810-7821 (2017). https://doi.org/10.1021/ acscatal.7b02414

50. Y. Zhou, D.E. Doronkin, M.L. Chen, S.Q. Wei, J.D. Grunwaldt, Interplay of Pt and crystal facets of $\mathrm{TiO}_{2}$ : Co oxidation activity and operando XAS/drifts studies. ACS Catal. 6(11), 7799-7809 (2016). https://doi.org/10.1021/acscatal.6b01509

51. S.R. Bare, S.D. Kelly, F.D. Vila, E. Boldingh, E. Karapetrova et al., Experimental (XAS, STEM, TPR, and XPS) and theoretical (DFT) characterization of supported rhenium catalysts. J. Phys. Chem. C 115(13), 5740-5755 (2011). https://doi. org/10.1021/jp1105218

52. J.J. Rehr, J.J. Kas, M.P. Prange, A.P. Sorini, Y. Takimoto, F. Vila, Ab initio theory and calculations of X-ray spectra. C. R. Phys. 10(6), 548-559 (2009). https://doi.org/10.1016/j. crhy.2008.08.004

53. P. Giannozzi, S. Baroni, N. Bonini, M. Calandra, R. Car et al., Quantum espresso: a modular and open-source software project for quantum simulations of materials. J. Phys.: Condes. Matter 21(39), 395502 (2009). https://doi.org/10.1088/0953$8984 / 21 / 39 / 395502$

54. C. Gougoussis, M. Calandra, A.P. Seitsonen, F. Mauri, Firstprinciples calculations of X-ray absorption in a scheme based on ultrasoft pseudopotentials: from alpha-quartz to high-Tc compounds. Phys. Rev. B 80(7), 075102 (2009). https://doi. org/10.1103/PhysRevB.80.075102

55. M. Taillefumier, D. Cabaret, A.M. Flank, F. Mauri, X-ray absorption near-edge structure calculations with the pseudopotentials: application to the K-edge in diamond and alpha-quartz. Phys. Rev. B 66(19), 195107 (2002). https:// doi.org/10.1103/PhysRevB.66.195107

56. S.J. Clark, M.D. Segall, C.J. Pickard, P.J. Hasnip, M.J. Probert, K. Refson, M.C. Payne, First principles methods using castep. Z. Kristall. 220(5-6), 567-570 (2005). https://doi. org/10.1524/zkri.220.5.567.65075

57. A. Baby, H. Lin, A. Ravikumar, C. Bittencourt, H.A. Wegner, L. Floreano, A. Goldoni, G. Fratesi, Lattice mismatch drives spatial modulation of corannulene tilt on $\operatorname{Ag}(111)$. J. Phys. Chem. C 122(19), 10365-10376 (2018). https://doi. org/10.1021/acs.jpcc.7b11581

58. B.P. Klein, N.J. van der Heijden, S.R. Kachel, M. Franke, C.K. Krug et al., Molecular topology and the surface chemical bond: alternant versus nonalternant aromatic systems as functional structural elements. Phys. Rev. X 9(1), 011030 (2019). https://doi.org/10.1103/PhysRevX.9.011030

59. A. Ugolotti, S.S. Harivyasi, A. Baby, M. Dominguez, A.L. Pinardi et al., Chemisorption of pentacene on $\mathrm{Pt}(111)$ with a little molecular distortion. J. Phys. Chem. C 121(41), 2279722805 (2017). https://doi.org/10.1021/acs.jpcc.7b06555

60. L. Triguero, L.G.M. Pettersson, H. Agren, Calculations of near-edge X-ray-absorption spectra of gas-phase and chemisorbed molecules by means of density-functional and transition-potential theory. Phys. Rev. B 58(12), 8097-8110 (1998). https://doi.org/10.1103/PhysRevB.58.8097

61. K. Diller, R.J. Maurer, M. Muller, K. Reuter, Interpretation of X-ray absorption spectroscopy in the presence of surface hybridization. J. Chem. Phys. 146(21), 214701 (2017). https ://doi.org/10.1063/1.4984072

62. V.A. Saveleva, L. Wang, D. Teschner, T. Jones, A.S. Gago et al., Operando evidence for a universal oxygen evolution mechanism on thermal and electrochemical iridium oxides. J. Phys. Chem. Lett. 9(11), 3154-3160 (2018). https://doi. org/10.1021/acs.jpclett.8b00810

63. H.Y. Wang, S.F. Hung, H.Y. Chen, T.S. Chan, H.M. Chen, B. Liu, In operando identification of geometrical-site-dependent water oxidation activity of spinel $\mathrm{Co}_{3} \mathrm{O}_{4}$. J. Am. Chem. Soc. 138(1), 36-39 (2016). https://doi.org/10.1021/jacs.5b10525

64. T. Vitova, J. Hormes, K. Peithmann, T. Woike, X-ray absorption spectroscopy study of valence and site occupation of copper in $\mathrm{LiNbO}_{3}: \mathrm{Cu}$. Phys. Rev. B 77(14), 144103 (2008). https ://doi.org/10.1103/PhysRevB.77.144103

65. H.Y. Wang, S.F. Hung, Y.Y. Hsu, L.L. Zhang, J.W. Miao, T.S. Chan, Q.H. Xiong, B. Liu, In situ spectroscopic identification of $\mu$-OO bridging on spinel $\mathrm{Co}_{3} \mathrm{O}_{4}$ water oxidation electrocatalyst. J. Phys. Chem. Lett. 7(23), 4847-4853 (2016). https ://doi.org/10.1021/acs.jpclett.6b02147

66. A. Jentys, Estimation of mean size and shape of small metal particles by EXAFS. Phys. Chem. Chem. Phys. 1(17), 40594063 (1999). https://doi.org/10.1039/a904654b

67. A.I. Frenkel, A. Yevick, C. Cooper, R. Vasic, Modeling the structure and composition of nanoparticles by extended X-ray absorption fine-structure spectroscopy. Annu. Rev. Anal. Chem. 4, 23-39 (2011). https://doi.org/10.1146/annurev-anche m-061010-113906 
68. A.I. Frenkel, Solving the structure of nanoparticles by multiple-scattering EXAFS analysis. J. Synchrotron Radiat. 6, 293-295 (1999). https://doi.org/10.1107/S0909049598017786

69. D.K. Bediako, B. Lassalle-Kaiser, Y. Surendranath, J. Yano, V.K. Yachandra, D.G. Nocera, Structure-activity correlations in a nickel-borate oxygen evolution catalyst. J. Am. Chem. Soc. 134(15), 6801-6809 (2012). https://doi.org/10.1021/ ja301018q

70. M. Yoshida, Y. Mitsutomi, T. Mineo, M. Nagasaka, H. Yuzawa, N. Kosugi, H. Kondoh, Direct observation of active nickel oxide cluster in nickel borate electrocatalyst for water oxidation by in situ O K-edge X-ray absorption spectroscopy. J. Phys. Chem. C 119(33), 19279-19286 (2015). https://doi. org/10.1021/acs.jpcc.5b06102

71. M.W. Kanan, J. Yano, Y. Surendranath, M. Dinca, V.K. Yachandra, D.G. Nocera, Structure and valency of a cobaltphosphate water oxidation catalyst determined by in situ X-ray spectroscopy. J. Am. Chem. Soc. 132(39), 13692-13701 (2010). https://doi.org/10.1021/ja1023767

72. U. Tylus, Q.Y. Jia, K. Strickland, N. Ramaswamy, A. Serov, P. Atanassov, S. Mukerjee, Elucidating oxygen reduction active sites in pyrolyzed metal-nitrogen coordinated non-preciousmetal electrocatalyst systems. J. Phys. Chem. C 118(17), 8999-9008 (2014). https://doi.org/10.1021/jp500781v

73. X.X. Wang, D.A. Cullen, Y.T. Pan, S. Hwang, M.Y. Wang et al., Nitrogen-coordinated single cobalt atom catalysts for oxygen reduction in proton exchange membrane fuel cells. Adv. Mater. 30(11), 1706758 (2018). https://doi.org/10.1002/ adma.201706758

74. H.G. Zhang, S. Hwang, M.Y. Wang, Z.X. Feng, S. Karakalos et al., Single atomic iron catalysts for oxygen reduction in acidic media: particle size control and thermal activation. J. Am. Chem. Soc. 139(40), 14143-14149 (2017). https://doi. org/10.1021/jacs.7b06514

75. H. Funke, A.C. Scheinost, M. Chukalina, Wavelet analysis of extended X-ray absorption fine structure data. Phys. Rev. B 71(9), 094110 (2005). https://doi.org/10.1103/PhysR evB.71.094110

76. H. Funke, M. Chukalina, A.C. Scheinost, A new FEFF-based wavelet for EXAFS data analysis. J. Synchrotron Radiat. 14, 426-432 (2007). https://doi.org/10.1107/S0909049507031901

77. H.B. Zhang, P.F. An, W. Zhou, B.Y. Guan, P. Zhang, J.C. Dong, X.W. Lou, Dynamic traction of lattice-confined platinum atoms into mesoporous carbon matrix for hydrogen evolution reaction. Sci. Adv. 4(1), eaao6657 (2018). https://doi. org/10.1126/sciadv.aao6657

78. L.T. Qu, Y. Liu, J.B. Baek, L.M. Dai, Nitrogen-doped graphene as efficient metal-free electrocatalyst for oxygen reduction in fuel cells. ACS Nano 4(3), 1321-1326 (2010). https:// doi.org/10.1021/nn901850u

79. M. Newville, Fundamentals of XAFS. Rev. Mineral. Geochem. 78, 33-74 (2014). https://doi.org/10.2138/rmg.2014.78.2

80. M.L. Baker, M.W. Mara, J.J. Yan, K.O. Hodgson, B. Hedman, E.I. Solomon, K- and l-edge X-ray absorption spectroscopy (XAS) and resonant inelastic X-ray scattering (RIXS) determination of differential orbital covalency (DOC) of transition metal sites. Coord. Chem. Rev. 345, 182-208 (2017). https:// doi.org/10.1016/j.ccr.2017.02.004

81. M. Wang, B. Han, J. Deng, Y. Jiang, M. Zhou et al., Influence of Fe substitution into $\mathrm{LaCOO}_{3}$ electrocatalysts on oxygenreduction activity. ACS Appl. Mater. Interfaces 11(6), 56825686 (2019). https://doi.org/10.1021/acsami.8b20780

82. C.J. Pelliccione, E.V. Timofeeva, J.P. Katsoudas, C.U. Segre, In situ Ru K-edge X-ray absorption spectroscopy study of methanol oxidation mechanisms on model submonolayer Ru on Pt nanoparticle electrocatalyst. J. Phys. Chem. C 117(37), 18904-18912 (2013). https://doi.org/10.1021/jp404342z

83. L.R. Merte, F. Behafarid, D.J. Miller, D. Friebel, S. Cho et al., Electrochemical oxidation of size-selected Pt nanoparticles studied using in situ high-energy-resolution X-ray absorption spectroscopy. ACS Catal. 2(11), 2371-2376 (2012). https:// doi.org/10.1021/cs300494f

84. K. Sasaki, K.A. Kuttiyiel, D. Su, R.R. Adzic, Platinum monolayer on IrFe core-shell nanoparticle electrocatalysts for the oxygen reduction reaction. Electrocatalysis 2(2), 134-140 (2011). https://doi.org/10.1007/s12678-011-0048-Z

85. D. Friebel, D.J. Miller, C.P. O'Grady, T. Anniyev, J. Bargar et al., In situ X-ray probing reveals fingerprints of surface platinum oxide. Phys. Chem. Chem. Phys. 13(1), 262-266 (2011). https://doi.org/10.1039/c0cp01434f

86. J. Suntivich, W.T. Hong, Y.L. Lee, J.M. Rondinelli, W.L. Yang et al., Estimating hybridization of transition metal and oxygen states in perovskites, from $\mathrm{O} \mathrm{K}$-edge X-ray absorption spectroscopy. J. Phys. Chem. C 118, 1856-1863 (2014). https:// doi.org/10.1021/jp410644j

87. Y. Wu, H. Fu, A. Roy, P.F. Song, Y.C. Lin, O. Kizilkaya, J. Xu, Facile one-pot synthesis of 3D graphite- $\mathrm{SiO}_{2}$ composite foam for negative resistance devices. RSC Adv. 7(66), 41812-41818 (2017). https://doi.org/10.1039/c7ra07465d

88. O. Muller, M. Nachtegaal, J. Just, D. Lutzenkirchen-Hecht, R. Frahm, Quick-EXAFS setup at the superxas beamline for in situ X-ray absorption spectroscopy with $10 \mathrm{~ms}$ time resolution. J. Synchrotron Radiat. 23, 260-266 (2016). https://doi. org/10.1107/S1600577515018007

89. X.Q. Yu, Q. Wang, Y.N. Zhou, H. Li, X.Q. Yang et al., High rate delithiation behaviour of $\mathrm{LiFePO}_{4}$ studied by quick $\mathrm{X}$-ray absorption spectroscopy. Chem. Commun. 48(94), 1153711539 (2012). https://doi.org/10.1039/c2cc36382h

90. M. Goesten, E. Stavitski, E.A. Pidko, C. Gucuyener, B. Boshuizen et al., The molecular pathway to ZIF-7 microrods revealed by in situ time-resolved small- and wide-angle X-ray scattering, quick-scanning extended X-ray absorption spectroscopy, and DFT calculations. Chem. Eur. J. 19(24), 7809-7816 (2013). https://doi.org/10.1002/chem.201204638

91. J. Li, F. Che, Y. Pang, C. Zou, J.Y. Howe et al., Copper adparticle enabled selective electrosynthesis of n-propanol. Nat. Commun. 9(1), 4614 (2018). https://doi.org/10.1038/s4146 7-018-07032-0

92. S. Ozawa, H. Matsui, N. Ishiguro, Y. Tan, N. Maejima et al., Operando time-resolved X-ray absorption fine structure study for $\mathrm{Pt}$ oxidation kinetics on $\mathrm{Pt} / \mathrm{C}$ and $\mathrm{Pt}_{3} \mathrm{CO} / \mathrm{C}$ cathode catalysts by polymer electrolyte fuel cell voltage operation 
synchronized with rapid $\mathrm{O}_{2}$ exposure. J. Phys. Chem. C 122(26), 14511-14517 (2018). https://doi.org/10.1021/acs. jpcc.8b02541

93. Y.J. Yan, W.M. Zhang, J.W. Che, Time-frequency theory of pump-probe absorption spectroscopy. J. Chem. Phys. 106(6), 2212-2224 (1997). https://doi.org/10.1063/1.473146

94. G. Khitrova, P.R. Berman, M. Sargent, Theory of pump probe spectroscopy. J. Opt. Soc. Am. B 5(1), 160-170 (1988). https ://doi.org/10.1364/Josab.5.000160
95. E. Goulielmakis, Z.H. Loh, A. Wirth, R. Santra, N. Rohringer et al., Real-time observation of valence electron motion. Nature 466(7307), 739-743 (2010). https://doi.org/10.1038/ nature09212

96. C.J. Milne, R.M. Van der Veen, V.T. Pham, F.A. Lima, H. Rittmann-Frank et al., Ultrafast X-ray absorption studies of the structural dynamics of molecular and biological systems in solution. Chimia 65(5), 303-307 (2011). https://doi. org/10.2533/chimia.2011.303 